\title{
IMPLEMENTACIÓN Y EVOLUCIÓN DE LOS DERECHOS CONTENIDOS EN EL CONVENIO OIT 169
}

\author{
APORTE DE LA JURISPRUDENCIA Y PRONÓSTICO \\ DE DESARROLLO FUTURO DE SUS IMPLICANCIAS \\ AMBIENTALES Y REGULATORIAS ${ }^{1}$
}

\author{
Andrés Fernández Alemany \\ y Cristhian de la Piedra Ravanal
}

\begin{abstract}
El presente trabajo tiene por finalidad efectuar un análisis sobre la forma en que debería darse efecto a los derechos reconocidos en el Convenio 169 de la Organización Internacional del Trabajo sobre Pueblos Indígenas y Tribales en Países Independientes. En particular, la atención se focaliza en aquellos derechos reconocidos por el Convenio que tienen una relación más directa con la utilización de recursos naturales, tierras y territorios, como también con el deber general de consulta frente a medidas legislativas o administrativas susceptibles de afectarles directamente. El trabajo intenta un enfoque práctico, para lo cual se consideran especialmente las implicancias
\end{abstract}

Andrés Fernández. Abogado de la Universidad de Chile. Magíster en Derecho de la Universidad de Pennsylvania. Abogado asesor en materias ambientales y regulatorias del estudio Vial y Fernández Asociados. Ex académico de las universidades Católica de Chile, del Desarrollo y Adolfo Ibáñez.

Cristhian de la Piedra. Abogado de la Universidad de Valparaíso. Magíster en Derecho Ambiental y Políticas Públicas de la Universidad de Kent, Canterbury. Abogado asesor en materias ambientales y regulatorias del estudio Vial y Fernández Asociados.

${ }^{1}$ Agradecemos la valiosa colaboración de la abogada Beatriz Recart Apfelbeck del estudio Vial y Fernández Abogados.

Estudios Públicos, 121 (verano 2011). 
ambientales y regulatorias que podrían derivarse de su entrada en vigencia, tomando en cuenta los precedentes de orden constitucional, judicial y administrativo que se han elaborado en el último tiempo. Finalmente, se identifican y analizan las materias que podrían acarrear modificaciones regulatorias como consecuencia de la entrada en vigencia del Convenio, teniendo en cuenta que la actual institucionalidad chilena, en muchos casos, ya contempla los mecanismos adecuados para el ejercicio de los derechos en él contenidos.

Palabras clave: Convenio 169; pueblos indígenas; derecho de consulta; utilización de recursos naturales, tierras y territorios; exigibilidad directa; disposiciones programáticas; principio de flexibilidad; Tribunal Constitucional; Corte Suprema; SEIA. Recibido y aceptado: enero 2011.

\section{INTRODUCCIÓN}

$\mathrm{E}_{1}$

Convenio OIT 169 (Convenio) es un tratado internacional que establece obligaciones para los Estados que lo ratifican ${ }^{2}$. Así por ejemplo, el artículo 2 (1) señala que "Los gobiernos deberán asumir la responsabilidad de desarrollar, con la participación de los pueblos interesados, una acción coordinada y sistemática con miras a proteger los derechos de esos pueblos y a garantizar el respeto de su integridad"3.

${ }^{2}$ Convenio No 169 de la Organización Internacional del Trabajo (OIT) sobre Pueblos Indígenas y Tribales en Países Independientes. El Convenio fue aprobado por la Cámara de Diputados en el año 2000, con un quórum de 72 diputados, y el día 4 de marzo de 2008 por el Senado, con un quórum de 36 senadores, siendo promulgado mediante DS No 236 de 2 de octubre de 2008 y publicado en el Diario Oficial el 14 de octubre de 2008. Sin embargo, su vigencia comenzó el 15 de septiembre de 2009, esto es, doce meses después de la fecha en que fue registrada su ratificación, según lo dispone el artículo 38 párrafo tercero del Convenio.

${ }^{3}$ Como consecuencia de esta obligación general que recae sobre los Estados, el Convenio se encarga de precisar obligaciones específicas con el objeto de lograr el mayor desarrollo de los derechos reconocidos a los pueblos indígenas, tales como las establecidas en el artículo 6 donde se establece el deber de implementar los procedimientos adecuados con el objeto de consultar a los pueblos indígenas; artículo 7 (3) con relación al deber de efectuar estudios para evaluar la incidencia social, espiritual y cultural y sobre el medio ambiente que las actividades económicas puedan tener sobre dichos pueblos; artículo 14 (2) en cuanto al deber de determinar las tierras que ocupan tradicionalmente y garantizar su derecho de propiedad y posesión; artículo 15 (2) relativo al deber de consultar a los pueblos interesados a fin de determinar si los intereses de los pueblos se podrían ver perjudicados, tratándose de la prospección o explotación de recursos naturales minerales u otros del subsuelo que pertenezcan al Estado, etc. 
De acuerdo con lo expresado, la responsabilidad directa en garantizar los derechos contemplados en el Convenio corresponde al Estado, el cual deberá adoptar una serie de medidas tendientes a darle efecto. En el cumplimiento de este deber, el artículo 37 del Convenio contempla una regla o principio de flexibilidad al establecer que "La naturaleza y el alcance de las medidas que se adopten para dar efecto al presente Convenio deberán determinarse con flexibilidad, teniendo en cuenta las condiciones propias de cada país".

Lo anterior tiene especial relevancia en cuanto a la exigibilidad directa de los derechos reconocidos en el Convenio, como de los medios que el Estado puede emplear para dar efecto al Convenio, por cuanto dichas medidas deben adoptarse considerando las condiciones económicas, jurídicas, sociales y culturales del país.

Las medidas que se adopten para dar efecto al Convenio también suponen algún margen de flexibilidad en cuanto a su "naturaleza y alcance".

Ello estaría indicando que los Estados no están sujetos a normas estrictas al momento de definir aquellas medidas que consideren como más adecuadas y pertinentes para dar efecto a los derechos que se reconocen en el Convenio. En este sentido, los Estados podrían recurrir a los procedimientos que consideren más idóneos, con la única limitación de dar cumplimiento con los objetivos o estándares que establece el Convenio. Esto último resulta relevante de considerar en relación con la forma de dar cumplimiento a los derechos de consulta y participación respecto de los cuales los Estados, invocando el principio de flexibilidad, podrían estimar que las medidas para dar efecto a dichos derechos ya se encuentran recogidas en el ordenamiento jurídico nacional.

Tal como se ha expresado, el Convenio sólo contempla obligaciones para los Estados de establecer medidas para dar efecto al Convenio $^{4}$. Sin embargo, cabe señalar que la falta o insuficiencia de dichas medidas podría acarrear impactos jurídicos para los administrados.

${ }^{4}$ El Tribunal Constitucional, según se explicará más adelante, expresa esta visión calificando la mayoría de las disposiciones del Convenio como no autoejecutables, por lo que para que produzcan efecto podrían requerir de la dictación de normativa. Al respecto el tribunal indicó: "Las segundas (no autoejecutables), son aquellas que requieren para su entrada en vigencia de la dictación de leyes, reglamentos o decretos que las implementen y, en tal evento, las hagan aplicables como fuente del derecho interno. En otras palabras, imponen la obligación al Estado, para que en uso de sus potestades públicas, sancione la normativa necesaria para que por esa vía les dé vigencia efectiva". (Tribunal Constitucional, sentencias Rol No 309 del 4 de agosto de 2000, considerando 48.) 
Esta situación puede producirse cuando el Estado falla en dar cumplimiento a las exigencias impuestas en el Convenio. Por ejemplo, si otorga autorizaciones o permisos sin contemplar un procedimiento de consulta previa en los casos que establece el Convenio, o cuando habiendo dado cumplimiento a las exigencias contempladas en el Convenio, por ejemplo implementando un procedimiento de consulta previa al otorgamiento de un permiso, se declare por un tribunal de justicia que dicho procedimiento no cumple con los estándares o exigencias contemplados en el Convenio ${ }^{5}$.

En estas circunstancias, la omisión por parte del Estado de garantizar la adecuada protección de los derechos reconocidos en el Convenio, especialmente el de consulta previa, podría llegar a afectar las autorizaciones o permisos y demás actos administrativos que se hayan otorgado a los administrados, toda vez que dichos actos habrían sido dictados con infracción a la normativa vigente. En efecto, en virtud del principio de juridicidad contemplado en los artículos 6 y 7 de la Constitución Política de la República, los órganos del Estado deben someter su acción a la Constitución y a las normas dictadas conforme a ella, y la contravención a estos principios puede acarrear la nulidad del acto.

Esta situación impone al Estado la exigencia legal de establecer reglas claras sobre la procedencia y formalidad de la consulta indígena. Por otro lado, ante la necesidad de evitar los riesgos de impugnaciones judiciales de sus autorizaciones o permisos, se impone sobre los administrados la exigencia práctica de asumir una estrategia proactiva con el objeto de tomar las prevenciones o resguardos para minimizar dichos riesgos ${ }^{6}$.

Frente a este escenario de incertidumbre y ante las altas expectativas que se han generado como consecuencia de la entrada en

${ }^{5}$ Tal como se explicará más adelante, el Tribunal Constitucional estimó que el derecho de consulta del artículo 6 (1) del Convenio, referido al caso en que se prevean medidas legislativas y administrativas que puedan afectar directamente a los pueblos indígenas, constituía un derecho autoejecutable o de aplicación directa. Como consecuencia de lo anterior, con la entrada en vigencia del Convenio se han presentado diversos recursos de protección por parte de comunidades indígenas reclamando la invalidación de actos administrativos como son las Resoluciones de Calificación Ambiental (RCA) emitidas por la autoridad ambiental, alegando la omisión de la consulta indígena. Esta misma situación podría plantearse respecto de decretos o reglamentos en caso que sean dictados sin la respectiva consulta indígena.

${ }^{6}$ World Bank Group, International Finance Corporation, "ILO Convention 169 and the Private Sector. Questions and Answers for IFC Clients", marzo 2007. 
vigencia del Convenio, el objetivo principal de este trabajo se centrará en efectuar un análisis de su implementación desde un punto de vista de su aplicación práctica, para lo cual se considerarán especialmente las implicancias ambientales y regulatorias que podrían derivarse como consecuencia de la entrada en vigencia del Convenio.

En relación con lo anterior, cabe acotar que el análisis de la implementación práctica se focalizará respecto de aquellos derechos reconocidos por el Convenio que tengan una relación más directa con el derecho de consulta, utilización de recursos naturales, tierras y territorios, por ser aquéllos los que más directamente se relacionan con autorizaciones o permisos otorgados a los administrados, y que han tenido mayor aplicación en los fallos de tribunales que se analizarán en este trabajo. Lo anterior, por cuanto el Convenio tiene un alcance más general, al reconocer derechos de distinta índole en el plano penal, de promoción social, de fomento cultural y de seguridad social que no se vinculan directamente con la materia antes señalada.

En concordancia con ello, el presente trabajo no entrará a analizar la jerarquía de tratado de derechos humanos que se le otorga al Convenio por parte de algunos autores ${ }^{7}$, por escapar a sus objetivos. En todo caso, cabe señalar que se ha originado un interesante debate en torno a esta materia, cuyo desarrollo convendrá seguir en el futuro.

Finalmente, este trabajo pretende identificar y analizar materias que podrían llegar a ser modificadas como consecuencia de la entrada en vigencia del Convenio.

\section{COMPROMISO POLÍTICO PARA LA IMPLEMENTACIÓN DEL CONVENIO}

En los últimos años la institucionalidad indígena ha estado sujeta a importantes novedades, siendo sin duda el Convenio el hito más relevante en materia de derechos indígenas desde la entrada en vigencia de la Ley $\mathrm{N}^{\mathrm{o}} 19.253$ (Ley Indígena) ${ }^{8}$.

${ }^{7}$ Santiago Montt Oyarzún y Manuel Matta Aylwin, "Una Visión Panorámica al Convenio OIT 169 y su Implementación en Chile”, 2011.

${ }^{8}$ Ley Indígena $N^{\circ} 19.253$ que Establece Normas sobre Protección, Fomento y Desarrollo de los Indígenas, y Crea la Corporación Nacional de Desarrollo Indígena, publicada en el Diario Oficial el 5 de octubre de 1993. 
El 1 de abril de 2008 se aprobó por parte de la administración de la Presidenta Bachelet una nueva política indígena denominada "Re-Conocer. Pacto Social por la Multiculturalidad”. Esta política contemplaba un plan de acción con medidas específicas, destinadas a dar cumplimiento a los compromisos asumidos durante su campaña presidencial.

El plan de acción se encontraba dividido en tres ejes fundamentales y el más relevante, desde el punto de vista del fortalecimiento jurídico de los derechos indígenas, fue el eje denominado "Sistema político, derechos e institucionalidad", el cual buscaba ampliar el reconocimiento de los derechos indígenas y su participación en el sistema político. Como un resultado de esta línea de acción, el Ejecutivo propuso diversos proyectos de ley tendientes a cumplir este objetivo y el resultado más concreto fue la aprobación del Convenio ${ }^{9}$.

En el cumplimiento de esta política se aprobó la creación de un Consejo Ministerial para Asuntos Indígenas ${ }^{10}$ y de un Comisionado Presidencial para Asuntos Indígenas que actuaría como su secretaría ejecutiva, y cuyo mandato era analizar y evaluar las propuestas sectoriales en materia indígena, emitir su opinión con relación a los proyectos de ley, sugerir directrices y formular recomendaciones en la implementación de dicha política indígena y del Convenio.

${ }^{9}$ Dentro de los proyectos de ley destinados a dar cumplimiento a este objetivo de fortalecer la institucionalidad y derechos indígenas podemos mencionar: (i) Boletín $\mathrm{N}^{\mathrm{o}} 5522$ de 23 de noviembre de 2007 destinado a obtener el Reconocimiento Constitucional de los Pueblos Indígenas. Dicho proyecto de ley fue objeto de indicaciones y se encuentra en discusión ante el Senado en su primer trámite constitucional, habiéndosele otorgado suma urgencia al día 15 de diciembre de 2010; (ii) Boletín $\mathrm{N}^{\circ} 6018$ de 6 de agosto de 2008 que crea la Subsecretaria de Asuntos Indígenas; (iii) Boletín No 672606 de 6 de octubre de 2009 que crea el Ministerio de Asuntos Indígenas y la Agencia de Desarrollo Indígena; (iv) Boletín No 6743-06 de 28 de octubre de 2009 que crea el Consejo de Pueblos Indígenas. Sin embargo, cabe señalar que ninguno de estos tres últimos proyectos de ley ha tenido algún tipo de tramitación y no cuentan con urgencia por parte del Ejecutivo.

${ }^{10}$ DS N ${ }^{\circ} 70 / 2008$ de 9 de mayo de 2008 de Mideplan que crea el Consejo Ministerial para Asuntos Indígenas, publicado en el Diario Oficial el 24 de junio de 2008. Dicho Consejo estaba integrado por diversos ministerios, entre ellos el Ministerio del Interior, Minsegpres, Educación, Obras Públicas, Bienes Nacionales, Agricultura, Vivienda y Urbanismo, Economía, y Medio Ambiente, y cuya presidencia le correspondía al Ministerio de Planificación. El Consejo tenía como función general la de asesorar al Presidente de la República en materias indígenas, como también la de cumplir funciones específicas de análisis y evaluación de propuestas sectoriales en materia indígena, emitir su opinión con relación a los proyectos de ley, formular recomendaciones, sugerir directrices, etc. 
Con el objeto de superar la tradicional radicación del tema indígena en un solo ministerio u órgano específico, un instructivo presidencial de 2008 ordenó a los distintos órganos de la administración del Estado crear unidades de asuntos indígenas dentro de cada ministerio; estudiar y readecuar políticas, planes y programas incorporando la pertinencia indígena, estableciendo un mandato a los órganos del Estado de implementar mecanismos de información y consulta frente a medidas legislativas y administrativas que pudieran afectar a los pueblos indígenas ${ }^{11}$.

A mayor abundamiento, la administración de la Presidenta Bachelet, ante la inminente entrada en vigencia del Convenio, procedió a encomendar al Comisionado de Asuntos Indígenas una serie de medidas. Así se elaboró una propuesta conocida como "Código de Conductas Responsables (CCR)"12 y se propuso realizar un diagnóstico completo de la normativa nacional, con la finalidad de clarificar si era necesario adecuar el actual ordenamiento jurídico a las disposiciones del Conve-

${ }^{11}$ Instructivo Presidencial No 005 de 25 de junio de 2008 que Implementa Iniciativas de Re-Conocer: Pacto Social por la Multiculturalidad. El primer ministerio que estableció dicha oficina de asuntos indígenas fue el Ministerio de Agricultura mediante Decreto $N^{\circ} 76$ de 20 agosto de 2008.

12 Comisionado Presidencial para Asuntos Indígenas, "Código de Conducta Responsable (CCR) para Inversiones en Tierras y Áreas de Desarrollo Indígena”, documento de discusión del Ministerio de Planificación (abril de 2009). Dicho documento fue elaborado por una consultora por encargo de Rodrigo Egaña, Comisionado Presidencial para Asuntos Indígenas, y presentado para su discusión en un taller convocado al efecto el 24 de abril de 2009. Por medio de este mecanismo, se pretendía implementar la consulta indígena contemplada en el Convenio. El CCR se proponía como un instrumento normativo que establecería un sistema de certificación de proyectos de inversión que se desarrollen en las Áreas de Desarrollo Indígena (ADI) y en tierras indígenas, con el objeto de verificar que se han dado cumplimiento a ciertas obligaciones o patrones de conducta (estándares mínimos de gestión responsable) que permitían al Consejo Nacional de Certificación, órgano público dependiente de Ministerio de Planificación, otorgar una autorización para la ejecución del proyecto. Finalmente dicha propuesta fue desechada por el Ministro Secretario General de la Presidencia de la época, ante la oposición generalizada por parte de organizaciones productivas, quienes manifestaron que el nuevo código generaría incertidumbre y un freno de inversiones en las zonas indígenas (Diario Financiero de 11 de mayo de 2009 y El Mercurio de 28 de mayo de 2009 y de 3 y 5 de junio de 2009) y por parte de las propias organizaciones indígenas (Alianza Territorial Wenten-Pewenche), por cuanto cuestionaban la forma en que el gobierno había llevado el proceso de participación del Convenio. Sin embargo, también cabe señalar que existieron voces disidentes dentro del movimiento indígena, como es el caso del líder mapuche Aucán Huilcamán del Consejo de Todas Las Tierras, que celebró la propuesta del CCR, ya que a su juicio permitiría frenar los proyectos en territorios indígenas, facilitando la negociación directa con las comunidades (La Tercera de 25 de mayo de 2009). 
nio ${ }^{13}$. El gobierno de la época, como una forma de optimizar el uso de los recursos públicos, generar intercambio fluido de información y de coordinación de los ministerios y servicios públicos, procedió a designar un Ministro Coordinador en materias indígenas, especialmente para coordinarse con las municipalidades de la Región de la Araucanía debido a los crecientes focos de tensión vividos en dicha región.

Finalmente, ante el fracaso de la propuesta de implementar el CCR, el Ministerio Secretaría General de la Presidencia dictó el DS $N^{\circ} 124 / 2009$ de 4 de septiembre de 2009, que contiene el Reglamento sobre Consulta y Participación Indígena (Reglamento de Consulta Indígena) $)^{14}$.

Cabe indicar que bajo la actual administración del Presidente Piñera, por medio del DS $\mathrm{N}^{\circ} 100$ de 7 de junio de 2010 de Mideplan, se dejó sin efecto el Consejo Ministerial para Asuntos Indígenas. A su vez, mediante el Decreto $\mathrm{N}^{\circ} 101$ de 7 de junio de 2010, se procedió a crear en su reemplazo un "Consejo de Ministros", modificando además su integración.

En forma adicional a estas modificaciones, se procedió a suprimir las atribuciones relacionadas con el seguimiento de la implementación del Convenio. En efecto, entre las facultades que anteriormente estaban radicadas en el Consejo Ministerial para Asuntos Indígenas se encontraba la de "Formular recomendaciones acerca de las acciones que se requieran para superar las dificultades que pudieran haber sido constatadas en la evaluación del estado de avance del plan de acción definido para la implementación de la Política Nacional Indígena y del Convenio $N^{o} 169$, de la Organización Internacional del Trabajo, antes individualizado".

Finalmente, cabe indicar que el cargo de Comisionado para Asuntos Indígenas fue derogado mediante DS N 99/2010 de 7 de julio

${ }^{13}$ El Comisionado de Asuntos Indígenas tenía planificado llamar a licitación a cinco universidades para los efectos de estudiar las adecuaciones normativas que fueran necesarias de implementar como consecuencia de la entrada en vigencia del Convenio. De los informes solicitados, sólo se contó con un informe borrador de la Universidad Diego Portales, que fue objeto de observaciones y que nunca llegó a tener una versión definitiva. Dicho proceso no continuó bajo la administración del Presidente Piñera, aparentemente debido a que se priorizaron las acciones en el corto y mediano plazo orientadas a ayudar a los indígenas que sufrieron pérdidas como consecuencia del terremoto del pasado 27 de febrero de 2010.

${ }^{14}$ DS N ${ }^{\circ} 124 / 2009$ de 4 de septiembre de 2009 de Mideplan que Reglamenta Artículo 34 de la Ley No 19.253 a Fin de Regular la Consulta y la Participación de los Pueblos Indígenas, publicado en el Diario Oficial con fecha 25 de septiembre de 2009. 
de 2010, creándose en su reemplazo el cargo de Asesor Especial, el que cumplirá las labores de Secretaría Ejecutiva del Consejo de Ministros y cuya sede es el Ministerio Secretaria General de la Presidencia.

Estos cambios institucionales podrían estar evidenciando un cambio en los énfasis de la actual administración, en el sentido que no sería necesario avanzar en la adopción de modificaciones legales y reglamentarias tendientes a la implementación del Convenio, sobre la base de que el actual ordenamiento jurídico sería suficiente para poder cumplirlo, en especial en lo relativo al derecho de consulta, y así poder enfocarse en otras materias sociales y económicas pendientes de la problemática indígena.

Nuestras reflexiones expresadas en la última parte de este trabajo concuerdan en gran medida con este análisis.

A mayor abundamiento, el criterio señalado se desprende de lo expresado por el Ejecutivo en la "Memoria" presentada por el Gobierno de Chile a la OIT acerca de las medidas adoptadas para dar efectividad a las disposiciones del Convenio durante el período septiembre 2009 a septiembre $2010^{15}$.

En efecto, en dicho documento se expresa que, en opinión del Ejecutivo, el DS 124 (Reglamento de Consulta Indígena) vendría a dar cumplimiento a las obligaciones de consulta de los artículos 6 y 7 del Convenio, por lo que dicha reglamentación sería adecuada para materializar o reglamentar la consulta indígena. Además, se agrega que la instancia de participación ciudadana que contempla la Ley $\mathrm{N}^{\circ} 19.300$ de Bases del Medio Ambiente ha permitido dar cabida a la participación de diversos estamentos sociales, entre ellos a las comunidades indígenas ${ }^{16}$.

De acuerdo a lo expresado, para los efectos del Convenio la actual administración del Presidente Piñera reconocería como válido el procedimiento de consulta establecido en el DS 124. Además, se valida la participación ciudadana establecida en la Ley 19.300, por lo

${ }^{15}$ Memoria presentada el 1 de septiembre de 2010 por el Gobierno de Chile en conformidad con las disposiciones del artículo 22 de la Constitución de la OIT correspondiente al período 15 de septiembre de 2009 al 15 de septiembre de 2010, acerca de las medidas adoptadas para dar efectividad a las disposiciones del Convenio.

${ }^{16}$ Se reconoce el carácter "transitorio" del Reglamento de Consulta, por lo que el Ejecutivo tiene la voluntad de revisar dicho Reglamento, para lo cual está desarrollando, con el objeto de perfeccionarlo, un proceso de consulta con las comunidades a través de mesas indígenas regionales. 
que, cumplido cualquiera de tales procedimientos, según sea el caso, se debiera entender cumplido el deber de consulta establecido en el Convenio.

\section{CONCEPTOS NUEVOS INCORPORADOS POR EL CONVENIO}

El Convenio incorpora varios conceptos que determinan el alcance de los derechos que se reconocen en él. Entre ellos, el concepto de territorio delimita el ámbito espacial en el cual pueden ejercerse ciertos derechos vinculados a la utilización de los recursos naturales. Por otro lado, la definición de pueblos indígenas resulta relevante por cuanto define la naturaleza jurídica de la potestad que tienen las comunidades en relación con el derecho de consulta y participación.

\section{III.1. Concepto de territorio indígena}

El artículo 13 del Convenio señala que el término tierras que se utiliza para los efectos del artículo 15 (derecho a participar en la utilización, administración y conservación de los recursos naturales existentes en sus tierras) y artículo 16 (derecho a no ser trasladados de sus tierras) deberán incluir el concepto de territorio. En otras palabras, cada vez que el Convenio hace referencia a la palabra tierras respecto de los derechos reconocidos por los artículos 15 y 16, éstos podrán ser exigibles también respecto de los territorios indígenas.

Para estos efectos, el artículo $13 \mathrm{~N}^{\circ} 2$ define territorio como "la totalidad del hábitat de las regiones que los pueblos interesados ocupan o utilizan de alguna otra manera".

De acuerdo a lo expresado, la noción de "territorio" tendrá implicancias jurídicas con relación a los derechos reconocidos en los artículos 15 y 16, por lo que el derecho a participar en la utilización, administración y conservación de los recursos naturales y a no ser relocalizados, puede hacerse exigible respecto de sus tierras, entendiéndose por tales las señaladas en el artículo 12 de la Ley Indígena ${ }^{17}$, como tam-

17 (i) Aquellas que las personas o comunidades indígenas actualmente ocupan en propiedad o posesión provenientes de determinados títulos; (ii) aquellas que históricamente han ocupado y poseen las personas o comunidades indígenas reconocidas, siempre que sus derechos se inscriban en el Registro de Tierras Indígenas; (iii) aquellas que, proviniendo de los títulos y modos referidos en los números precedentes, se declaren a futuro pertenecientes en propiedad a personas o comunidades indígenas por los Tribunales de Justicia; y (iv) aquellas que indígenas o sus comunidades reciban a título gratuito del Estado. 
bién el territorio indígena, es decir, el hábitat que ocupan o utilizan para sus actividades tradicionales o de subsistencia.

El concepto de territorio reconocido por el Convenio recoge una histórica aspiración de los pueblos indígenas de incorporar dentro de tal concepto, no solamente las tierras que "tradicionalmente ocupan", es decir, respecto de las cuales se dan los requisitos de la posesión, entendiéndose ésta como la ocupación efectiva de un bien, en forma continua y pacífica, con ánimo de señor o dueño, sino también un concepto más general y menos jurídico que "cubre la totalidad del hábitat de las regiones que los pueblos interesados ocupan o utilizan de alguna otra manera".

Esta definición de territorio comprende la idea de áreas que constituyen el ámbito tradicional de sus actividades sociales, económicas y culturales, de manera que el territorio indígena no se agote en aquellas tierras que efectivamente ocupan o explotan, sino que también comprende aquellos terrenos ocupados ocasionalmente para labores de pastoreo, subsistencia o realización de ceremonias religiosas.

El concepto de territorio va más allá del concepto tradicional de tierra, es decir, el espacio físico delimitado jurídicamente. En este caso el Convenio recurre a la noción que en la antropología social es denominada territorio vivido, es decir, un concepto dinámico de territorio que se construye según la experiencia colectiva de quienes lo habitan, más allá de sus límites puramente político-administrativo o jurídicos, que en el caso de comunidades indígenas pueden estar dados por la realización de ritos o celebraciones culturales, comerciales o religiosas.

De esta forma, el territorio estaría comprendido por las áreas que integran el ámbito tradicional de sus actividades económicas, sociales y culturales. Éste podría ser el caso de terrenos ocupados ocasionalmente para labores de pastoreo o de terrenos ocupados para la realización de ceremonias religiosas, donde no existe una ocupación permanente, pero donde las comunidades desarrollan actividades de índole cultural o de subsistencia tradicional.

En este sentido, la Guía del Convenio elaborado por la OIT señala que la tierra y los territorios que habitan los pueblos indígenas "Son los lugares donde vivieron sus ancestros y donde se desarrollan su historia, conocimientos, prácticas de sustento y creencias. Para gran parte 
de los pueblos, el territorio tiene un significado sagrado o espiritual, que va mucho más allá del aspecto productivo y económico de la tierra"18.

Siguiendo los criterios de la Guía del Convenio 169 OIT, las siguientes áreas pueden constituir territorio:

- $\quad$ los lugares donde vivieron sus ancestros y donde se desarrolla su historia, conocimientos, prácticas de sustento y creencias

- $\quad$ incluye los bosques, ríos, montañas y mares costeros y tanto la superficie como el subsuelo

- base de la economía y las estrategias de sustento, y de sus instituciones tradicionales.

En el ámbito nacional, la Corte Suprema (CS) ha dado reconocimiento a la noción de territorio indígena del Convenio. Así lo señaló al acoger una solicitud de regularización de aguas presentada por la Comunidad Indígena Aimara de Chusmiza-Usmagama. Dicha comunidad recurrió al procedimiento de regularización del artículo 2 transitorio inciso segundo del Código de Aguas, argumentándose que la presunción de dominio a que hace referencia el artículo 64 de la Ley Indígena, esto es, que se consideran bienes de propiedad y uso de la comunidad indígena, no sólo se refiere a las aguas que se encuentren en "terrenos de la comunidad", sino también se hacía extensiva a aquellas que se encontraban en sus territorios. Sobre este punto nos referiremos en detalle al analizar la jurisprudencia sobre la materia.

La delimitación del territorio indígena es una materia de extrema complejidad, más aún si se considera que en el plano ambiental podría llegar a constituir un requisito de exigencia para la presentación de un Estudio de Impacto Ambiental (EIA). En efecto, según establece el artículo 8 del Reglamento del Sistema de Evaluación de Impacto Ambiental (SEIA) contenido en el DS Nº 95/2001 del Minsegpres, se requerirá de un EIA cuando el proyecto genere o presente alteración significativa de los sistemas de vida y costumbres de grupos humanos, para lo cual deberán considerarse la dimensión antropológica (manifestaciones de la cultura, ceremonias religiosas, peregrinaciones, procesiones, celebraciones, festivales, torneos, ferias y mercados) y las variables socioeconómica (presencia de actividades productivas dependientes de la extracción de recursos naturales, ya sea en forma individual o colectiva).

${ }^{18}$ Departamento de Normas Internacionales del Trabajo, OIT, Una Guía sobre el Convenio $N^{\circ} 169$ OIT, 2009, p. 91. 
Por otro lado el artículo 11 (d) del Reglamento del SEIA señala que se requerirá de un EIA cuando el proyecto genere o presente alteración de sitios con valor antropológico o histórico, para lo cual se considerará "la proximidad a lugares o sitios en que se lleven a cabo manifestaciones propias de la cultura o folclore de algún pueblo, comunidad o grupo humano".

En este sentido, el territorio indígena no sólo comprende el hábitat natural que utilizan las comunidades para sus fines productivos o comerciales, sino también el hábitat cultural que comprende el desarrollo de actividades culturales o religiosas.

Sobre esta materia debe considerarse la noción de "patrimonio cultural inmaterial", que ha sido incorporada a nuestro ordenamiento jurídico mediante la reciente aprobación de la "Convención para la Salvaguardia del Patrimonio Cultural Inmaterial de la Unesco", y que fuera publicado el 13 de marzo de 2009. Dicha Convención está plenamente vigente, desde el momento que ha sido ratificada o aceptada por más de 110 países, incluido Chile en el número 106. Contempla una amplia definición de patrimonio cultural inmaterial que involucra a tradiciones, expresiones orales, usos sociales, rituales, actos festivos, usos relacionados con la naturaleza y el universo. En general, comprende al patrimonio que es recreado constantemente por las comunidades en función de su entorno, interacción con la naturaleza e historia, otorgándoles un sentimiento de identidad y continuidad cultural, según señala el artículo 2 (1) y (2) de la Convención.

Esta noción dinámica del territorio es susceptible de generar un escenario de complejidad frente a medidas o proyectos que pretendan intervenir territorio indígena en los alcances ya explicados. Sin embargo, para que se configure el territorio indígena será necesario que los pueblos interesados ocupen o utilicen de alguna manera dichos espacios. Considerar esta circunstancia también nos permite diferenciar los territorios indígenas identificados por quienes promueven que la extensión de éstos se encuentra dada por sus referencias pre-coloniales, sin que sea exigencia que exista ocupación efectiva de dichos territorios por parte de las comunidades ${ }^{19}$.

${ }^{19}$ Nancy Yáñez y Raúl Molina, La Gran Minería y los Derechos Indígenas en el Norte de Chile, 2008. Los autores indican que "Como hemos reiterado, la actual defensa de la propiedad de los recursos naturales indígenas frente a las compañías mineras se basa en la existencia de una ocupación territorial ancestral. El propósito es demostrar 
Un segundo elemento que nos permite delimitar el concepto de territorio indígena, no sólo en cuanto a la necesidad de que exista ocupación o utilización de ellos, se refiere a la limitación en cuanto a los derechos del Convenio al cual se aplica dicho concepto. En efecto, tal como se ha explicado anteriormente, el Convenio incorpora esta noción de territorio, referida únicamente a los derechos consagrados en los artículos 15 y 16, y no de manera amplia para los demás derechos reconocidos en dicho Convenio. En este sentido la aplicación del concepto de territorio para otros derechos como el de la consulta indígena resulta inadecuada, ya que en estos casos el elemento determinante para hacer exigible este derecho no se encuentra relacionado con un determinado territorio, sino con la necesidad de acreditar la "afectación directa" que produce una determinada medida administrativa o legislativa en dicha comunidad ${ }^{20}$.

\section{III.2. Concepto de pueblos indígenas o tribales}

Éste es el concepto más controvertido que utiliza el Convenio por sus implicancias en relación con la "libre determinación" de los pueblos. Por esta razón, durante el proceso de discusión parlamentaria de la Ley Indígena se dejó expresa constancia de acoger el planteamiento de evitar la utilización de tales expresiones, ocupando en su reemplazo la expresión "etnias o poblaciones indígenas"21.

que los indígenas ocupan tierras ancestrales, que en muchos casos conservan desde el periodo colonial y el republicano, y en algunos casos desde el periodo prehispánico", p. 49. Los autores agregan que la demarcación de estos territorios y la regularización de las tierras deben ser el resultado de un proceso de consulta y acuerdo de buena fe entre el Estado y los pueblos indígenas, "en el cual no procede aplicar criterios de ocupación efectiva y otros que tiendan a reducir los territorios de los indígenas", p. 236.

${ }^{20}$ Ilust. Corte de Apelaciones de Puerto Montt, sentencia de 27 de julio de 2010, recurso de protección Rol 36/2010 caratulado Comunidad Mapuche Huilliche Pepiukelén de Pargua en contra de la Empresa Pesquera Los Fiordos Ltda. La Corte de Apelaciones de Puerto Montt ordenó la paralización de las obras y la exigencia de retrotraer las cosas al estado anterior de su ejecución, debido a que dicho terreno constituiría "territorio indígena" y las comunidades debieron haber sido consultadas. Finalmente, la Corte Suprema si bien confirmó la sentencia, procedió a eliminar los considerandos noveno y décimo de la sentencia de la Corte de Apelaciones, en todo lo relativo a las tierras y territorios indígenas, limitándose a señalar que la actuación de la empresa afecta el medio ambiente de las comunidades vecinas. Sobre esta materia nos referiremos al analizar la jurisprudencia sobre la consulta indígena.

${ }^{21}$ Senado, sesión $\mathrm{N}^{\circ}$ 10, legislatura del 13 de julio de 1993, p. 1317. 
El Convenio incorporó la expresión pueblos a diferencia de lo que ocurría en el Convenio $\mathrm{N}^{\mathrm{o}} 107$, y que hacía referencia a "poblaciones". Sin embargo, el Convenio establece la siguiente salvedad en el artículo $1^{\circ} \mathrm{N}^{\mathrm{o}}$ 3: "La utilización del término pueblos en este convenio no deberá interpretarse en el sentido de que tenga implicancia alguna en lo que atañe a los derechos que pueda conferirse a dicho término en el derecho internacional".

De esta forma, el Convenio no adopta una posición en el sentido de reconocer un derecho a la libre determinación, que era precisamente una de las principales aspiraciones de los grupos indigenistas.

En la discusión de constitucionalidad que se dio al interior del Tribunal Constitucional se determinó por este tribunal que el concepto de pueblos debe ser entendido como "un conjunto de personas o grupos de personas de un país que poseen en común características culturales propias, que no se encuentran dotadas de potestades públicas y que tienen y tendrán derecho a participar y a ser consultadas, en materias que les conciernen, con estricta sujeción a Ley Suprema del respectivo Estado de cuya población forman parte. Ellos no constituyen un ente colectivo autónomo entre los individuos y el Estado"22.

En este sentido, la expresión "pueblos" no puede ser considerada como aquel grupo que detenta la soberanía o su ejercicio, asignándosele alguna potestad pública o de decisión, sino lo que se busca con esta definición es afirmar la identidad del grupo indígena y dotarlo de ciertos derechos especiales, pero como un grupo integrado a la nación chilena.

Tal como indicamos anteriormente, la clarificación de los límites de esta definición permitirá comprender a cabalidad cuál es el derecho que tienen las comunidades indígenas en el ejercicio del derecho de consulta y participación, en el sentido de que no gozan de potestades públicas y, por tanto, su opinión no constituye un veto o prohibición de realizar las medidas o proyectos que pudieran afectarles.

\section{DERECHOS RECONOCIDOS POR EL CONVENIO EN RELACIÓN CON LA TIERRA Y RECURSOS NATURALES}

El Convenio constituye un cambio de dirección respecto a la política anterior que promovía la asimilación de los pueblos indígenas

${ }^{22}$ Tribunal Constitucional, Rol No 309 del 4 de agosto de 2000, considerando 44 . 
en las sociedades mayoritarias ${ }^{23}$. En definitiva, es una superación del modelo que entendía a los indígenas como incapaces de salir de sus condiciones de pobreza o marginación por sí mismos, sin que mediara la acción del Estado tutelar.

Este Convenio propone un cambio en la visión paternalista o integracionista que establecía el Convenio $\mathrm{N}^{\circ} 107$ de 1957, al que reemplazó, que consiste en una nueva forma de relación entre el Estado y los pueblos indígenas, sobre la base del respeto de su dignidad y del reconocimiento de su plena capacidad para decidir y controlar su destino a través de sus propias instituciones, y para determinar el control de sus propios asuntos en forma igualitaria con los demás grupos que forman parte de la sociedad.

Conforme esta premisa, el Convenio reconoce una serie de derechos sobre la tierra y los recursos naturales, y exige por parte de los Estados que se consulte a los pueblos indígenas cuando éstos puedan ser afectados.

No obstante esta aspiración, el propio Convenio deja en claro desde el preámbulo que el reconocimiento de los derechos de los pueblos indígenas y tribales debe enmarcarse dentro de la legislación e institucionalidad vigente en cada país. Dicho preámbulo se refiere a "las aspiraciones de estos pueblos a asumir el control de sus propias instituciones, formas de vida y desarrollo económico y a mantener y fortalecer sus identidades, lenguas y religiones, dentro del marco de los estados donde viven".

En este sentido, el Convenio establece un mecanismo basado en el respeto recíproco, por el cual los Estados deben reconocer la contribución a la diversidad cultural y los derechos de los pueblos indígenas, considerando al mismo tiempo que éstos deben enmarcarse dentro del respeto de la legislación o marco jurídico que los propios Estados se han dado.

Como anteriormente se ha señalado, se consideró oportuno proceder a delimitar aquellos derechos reconocidos por el Convenio que tengan una relación más directa con la utilización de los recursos naturales, tierras y territorios. Con el objeto de facilitar el análisis de estos derechos reconocidos por el Convenio, se procedió a clasificarlos de la siguiente manera:

${ }^{23}$ James Anaya, “Los Derechos de los Pueblos Indígenas”, 2004, p. 691. 


\section{IV.1. Derechos en relación con las tierras}

1. Derecho a reclamar la propiedad de las tierras que han sido ocupadas por los pueblos (art. $14 \mathrm{~N}^{\circ} 1$ primera parte).

2. Derecho a utilizar las tierras que si bien no son ocupadas exclusivamente por ellos, han tenido un tradicional acceso (art. $14 \mathrm{~N}^{\circ} 1$ segunda parte).

\section{IV.2. Derechos en relación con la participación y consulta sobre recursos naturales existentes en sus tierras (territorios)}

3. Derecho a que los recursos naturales existentes en sus tierras sean protegidos especialmente (art.15 $\mathrm{N}^{\circ} 1$ primera parte).

4. Derecho a participar en la utilización, administración y conservación de los recursos naturales existentes en sus tierras (art. $15 \mathrm{~N}^{\circ} 1$ segunda parte).

5. Derecho a ser consultados en forma previa a la ejecución o autorización de obras de prospección o explotación de los minerales y recursos del subsuelo y otros que pertenezcan al Estado (art. $15 \mathrm{~N}^{\circ} 2$ ).

\section{IV.3. Derecho a participar de los beneficios y a ser indemnizados}

6. Derecho a participar de los beneficios que reporten las actividades que se ejecuten en sus tierras (art. $15 \mathrm{~N}^{\circ} 2$ primera parte).

7. Derecho a ser indemnizados por cualquier daño que puedan sufrir como resultado de las actividades que se ejecuten en sus tierras (art. $15 \mathrm{~N}^{\circ} 2$ segunda parte).

Sin perjuicio de estos derechos especiales con relación a las tierras, territorios y recursos naturales que se encuentren en ellos, se analizará en forma separada el derecho de consulta general del artículo $6 \mathrm{~N}^{\circ} 1$ frente a medidas legislativas y administrativas susceptibles de afectarles directamente.

\section{ANÁLISIS SOBRE LA CONSTITUCIONALIDAD DEL CONVENIO REALIZADO POR EL TRIBUNAL CONSTITUCIONAL}

En el año 2000, un grupo de 31 diputados solicitó la declaración de inconstitucionalidad de algunas de las disposiciones del Convenio ante el Tribunal Constitucional (TC). Sin embargo, el TC rechazó la so- 
licitud de inconstitucionalidad tanto en la forma como en el fondo, por cuanto se estableció que: (i) la mayoría de las disposiciones del Convenio tienen un carácter "programático", y por tanto no son autoejecutables; y (ii) aquellas que sí son autoejecutables no son contrarias a la Constitución Política del Estado ${ }^{24}$.

Sobre este punto conviene tener presente la distinción que realiza el TC entre normas autoejecutables y normas no autoejecutables o programáticas. En efecto, el TC ha señalado que "Los tratados, para su aplicación en el orden interno de un país, pueden contener dos tipos de cláusulas, denominadas por la doctrina 'self executing' y 'non self executing'. Las primeras, son las que tienen el contenido y precisión necesarios que las habilita para ser aplicadas sin otro trámite como fuente del derecho interno. En otros términos, son auto suficientes, y entran a la legislación nacional cuando el tratado que las contiene se incorpora al derecho vigente. Las segundas, son aquellas que requieren para su entrada en vigencia de la dictación de leyes, reglamentos o decretos que las implementen $\mathrm{y}$, en tal evento, las hagan aplicables como fuente del derecho interno. En otras palabras, imponen la obligación al Estado, para que en uso de sus potestades públicas, sancione la normativa necesaria para que por esa vía les dé vigencia efectiva"25.

Esta distinción resulta relevante desde el punto de vista de la exigibilidad de los derechos reconocidos, por cuanto por regla general las normas programáticas o no autoejecutables no pueden ser aplicadas directamente e imponen sobre el Estado el deber de adecuar la normativa para que sean exigibles. En virtud de lo anterior, sólo las normas del Convenio que sean calificadas de autoejecutables podrán ser reclamadas directamente ante los tribunales de justicia. Las normas que tienen un carácter programático sólo constituyen un deber para el Estado de adoptar las medidas que correspondan para que éstas tengan eficacia jurídica.

Cabe considerar que en el análisis de constitucionalidad que realizó el TC, éste declaró que sólo el artículo 6 número 1 letra (a) que

${ }^{24}$ Tribunal Constitucional Rol No 309 del 4 de agosto de 2000. Posteriormente, el TC emitió un nuevo pronunciamiento como parte del control de constitucionalidad de las leyes orgánicas constitucionales, como sería el caso de las normas que vienen a establecer modos de participación de los pueblos indígenas, tales como las contempladas en los artículos $6^{\circ}, \mathrm{N}^{\circ} 1$, letra a), y $\mathrm{N}^{\circ} 2, \mathrm{y}^{\circ}, \mathrm{N}^{\mathrm{o}} 1$, oración segunda, confirmando su constitucionalidad.

${ }^{25}$ Tribunal Constitucional Rol No 309 del 4 de agosto de 2000, considerando 48 . 
establece el derecho a la consulta indígena frente a medidas legislativas y administrativas que puedan afectarlos directamente y el artículo 7 número 1 oración final que establece el derecho a participar en la elaboración de planes, programas y políticas, constituyen normas autoejecutables, esto es, que no requieren de ninguna adecuación normativa para que sean aplicables.

\section{V.1. Derecho con relación a las tierras}

Con relación al derecho a reclamar la propiedad o posesión de las tierras que tradicionalmente ocupan (artículo $14 \mathrm{~N}^{\circ} 1$ primera parte) y el derecho a utilizar las tierras que si bien no son ocupadas exclusivamente por ellos, han tenido un tradicional acceso (artículo $14 \mathrm{~N}^{\circ} 1$ segunda parte), el TC estableció que las disposiciones del Convenio tienen un carácter programático.

Lo expresado por el TC quiere decir que sus disposiciones reflejan declaraciones pero no son ejecutables con el solo mérito del tratado. Esto se debe a que el lenguaje del Convenio utiliza expresiones tales como: "deberá reconocerse a los pueblos"; o "deberán tomarse medidas"; o "deberán instituirse procedimientos adecuados en el marco del sistema jurídico nacional".

Como consecuencia de lo anterior, el Convenio no sería suficiente por sí mismo para poner en ejecución los derechos que reconoce con relación a la reclamación del dominio y del derecho a utilizar tierras, sino que corresponderá al Estado dictar la legislación nacional o adecuar la existente, en caso de ser necesario, para que estos derechos puedan ser exigibles.

Lo anterior resulta coherente con el principio de flexibilidad a que hace referencia el artículo 34 del Convenio, que establece que las medidas que se adopten para dar efecto al Convenio deberán determinarse con flexibilidad, teniendo en cuenta las condiciones propias de cada país, entre las que se cuenta el sistema jurídico vigente.

El TC también efectúa otra declaración, al señalar que las medidas que el Convenio propone no quedan comprendidas en el marco del sistema jurídico de expropiaciones. Esta aclaración se efectuó a propósito del requerimiento de los diputados que precisamente reclamaban que de ratificarse el Convenio, el Estado asumiría la obligación de expropiar tierras reclamadas por organizaciones indígenas en su beneficio 
propio. El TC declaró que estas situaciones no quedan comprendidas en el sistema de expropiaciones ${ }^{26}$.

Por lo tanto, tal declaración no permitiría a las comunidades indígenas invocar el Convenio para exigir por parte del Estado que inicie un proceso de expropiación de tierras o territorios que son legítimamente ocupados por terceros, por cuanto el sistema jurídico nacional dado por la Constitución y las leyes no da cabida a expropiaciones para tal efecto.

En este sentido, el Convenio no habría innovado en la legislación nacional, por cuanto la legislación chilena establece que para reivindicar el dominio se requiere acreditar la existencia de ocupación efectiva (tenencia), exclusiva y no clandestina. Según indicaremos más adelante, el Foro Permanente de las Naciones Unidas para Asuntos Indígenas comparte la opinión que para hacer efectivo este derecho debe existir ocupación actual para los efectos de reclamar la propiedad o posesión.

Con relación al derecho a utilizar tierras que no estén ocupadas exclusivamente por las comunidades, esta norma tampoco sería autoejecutable, por lo tanto para que se reconozca este derecho podría resultar necesario modificar la legislación interna. Lo anterior es sin perjuicio de las autorizaciones que su propietario pueda otorgar según analizaremos más adelante.

\section{V.2. Derechos en relación con la participación y consulta sobre recursos naturales existentes en sus tierras (territorios)}

Cabe precisar que el TC no se pronunció sobre la totalidad de los derechos que se contemplan en el artículo 15 , sino que específicamente en relación con el derecho de consulta previa a la ejecución o autorización de obras de prospección o explotación de los minerales, recursos del subsuelo $\mathrm{u}$ otros recursos existentes en las tierras indígenas.

A este respecto el TC volvió a confirmar su opinión de que esta disposición sólo tiene un carácter programático. El TC agrega que los procedimientos de consulta del Convenio ya se encuentran incorporados a la legislación interna, como ocurre, por ejemplo, con los artículos 26 al 31 de la Ley $N^{\circ} 19.300$ sobre Bases Generales del Medio Ambiente, al igual que los artículos 10, 11 y 34 de la Ley Indígena. Lo anterior

${ }^{26}$ Tribunal Constitucional Rol No 309 del 4 de agosto de 2000, considerando 66. 
estaría indicando, de acuerdo con la opinión del TC, lo innecesario de adecuar la normativa vigente para hacerse cargo de la consulta indíge$\mathrm{na}^{27}$.

En relación especifica con la consulta en caso de realización de labores de prospección o explotación, el TC señaló que "el Código de Minería contempla un claro procedimiento judicial para constituir las concesiones mineras, el que garantiza que todos los interesados pueden ser escuchados frente a una violación de sus derechos" ${ }^{28}$. En este sentido, el TC fue de la opinión que este derecho de consulta ya se encuentra garantizado en el actual procedimiento judicial.

Adicionalmente, como se explicó al analizar la definición de pueblos que da el Convenio, el TC concluye que éstos no están dotados de potestades públicas propias, en el sentido de que gocen de facultades o poderes públicos. Por esta razón, el TC estimó que el derecho de consulta que reconoce el Convenio queda enmarcado en lo dispuesto en el artículo $1^{\circ}$ de la Constitución Política, que establece un derecho genérico de participación que "asegura el derecho de las personas a participar con igualdad de oportunidades en la vida nacional" 29 .

Si se considera el pronunciamiento que el TC efectuó con relación a la definición de pueblos, en el sentido de que carecían de facultades o poderes públicos, es perfectamente posible concluir que implícitamente frente a esta consulta específica del artículo 15 no se contempla un derecho de veto frente a un proyecto que pretenda explotar recursos mineros u otros que pertenezcan al Estado que se encuentren en sus tierras o territorios. El propio TC concluye que "en esta parte el Convenio no compromete las bases constitucionales del régimen de concesiones mineras, ni afecta los derechos de los concesionarios" $"$.

\section{V.3. Con relación al derecho a participar de los beneficios y a ser indemnizados}

Con relación a estos derechos, el TC no mostró mayores reparos de legalidad por cuanto estimó que esta disposición también es meramente programática o declarativa, debido a que el Convenio utiliza el

\footnotetext{
${ }^{27}$ Tribunal Constitucional Rol No 309 del 4 de agosto de 2000, considerando 70 .

${ }^{28}$ Tribunal Constitucional Rol No 309 del 4 de agosto de 2000, considerando 71 .

${ }^{29}$ Tribunal Constitucional Rol No 309 del 4 de agosto de 2000, considerando 72.

${ }^{30}$ Tribunal Constitucional Rol No 309 del 4 de agosto de 2000, considerando 72.
} 
verbo rector "siempre que sea posible". En efecto, el artículo $15 \mathrm{~N}^{\circ} 2$ señala que "Los pueblos interesados deberán participar siempre que sea posible en los beneficios que reportan tales actividades, y percibir una indemnización equitativa por cualquier daño que puedan sufrir".

En opinión del TC, este derecho a la participación en los beneficios derivados de la explotación de recursos naturales debe entenderse en el sentido de que su aplicación debe ajustarse al régimen constitucional y legal de la propiedad minera ${ }^{31}$.

\section{PROHIBICIÓN DE MENOSCABAR LOS DERECHOS Y VENTAJAS GARANTIZADOS EN OTROS INSTRUMENTOS INTERNACIONALES}

Una de las principales dificultades que existen al momento de comprender los alcances del Convenio se presenta en relación con los derechos reconocidos en otros instrumentos internacionales que se vinculan con materias indígenas. Sobre este punto, el artículo 35 establece que las disposiciones del Convenio "no deberán menoscabar los derechos y las ventajas garantizados a los pueblos interesados en virtud de otros convenios y recomendaciones, instrumentos internacionales, tratados, o leyes, laudos, costumbres o acuerdos nacionales."

Esta disposición tiene su origen en el artículo 29 del Convenio $\mathrm{N}^{\circ} 107$ de la OIT, el cual establecía que "La aplicación de las disposiciones del presente Convenio no menoscabarán las ventajas garantizadas a las poblaciones en cuestión en virtud de las disposiciones de otros convenios o recomendaciones". A su vez esta disposición se basa en el artículo 19, párrafo 8 de la Constitución de la OIT, el cual dispone: "En ningún caso podrá considerarse que la adopción de un convenio o de una recomendación de la Conferencia, o la ratificación de un convenio por cualquier Miembro, menoscabará cualquier ley, sentencia, costumbre o acuerdo que garantice a los trabajadores condiciones más favorables que las que figuren en el convenio o en la recomendación".

Durante la discusión parlamentaria para la aprobación del Convenio surgió la petición de establecer una cláusula interpretativa del artículo 35, en el sentido de que éste sea sólo aplicable con relación a los tratados internacionales ratificados por Chile y que se encuentren vigentes, excluyéndose de esta forma a las recomendaciones. Lo anterior

\footnotetext{
${ }^{31}$ Tribunal Constitucional Rol No 309 del 4 de agosto de 2000, considerando 73.
} 
se debía a que el 13 de septiembre de 2007 la Asamblea General de la ONU aprobó la Declaración sobre Derechos de los Pueblos Indígenas, la que contó con el voto favorable del Gobierno de Chile ${ }^{32}$.

Frente a la alegada amplitud y vaguedad de los derechos reconocidos en la Declaración de la ONU (que adopta la forma jurídica de una Recomendación), y con el objeto de evitar una contradicción con los derechos reconocidos en el Convenio, se solicitó por parte de los parlamentarios incorporar una cláusula a fin de excluir a las "recomendaciones". Sin embargo, el Convenio fue aprobado sin dicha cláusula, solicitándose en cambio, por parte de la Comisión de Relaciones Exteriores del Senado, que el gobierno efectuara una consulta a la Secretaría de la OIT sobre el alcance jurídico de dicho artículo ${ }^{33}$.

La importancia de esta materia radica en que la Declaración sobre Derechos de los Pueblos Indígenas establece una serie de derechos que no estarían comprendidos en el Convenio, como es el caso del derecho a la libre determinación (art. 3); derecho a ser consultados para alcanzar el libre consentimiento previo e informado (art. 19); derecho a la autonomía y gobierno (art. 4); derecho a pertenecer a una comunidad (art. 9 y 33); derecho a propiedad intelectual (art. 31), entre otros ${ }^{34}$.

De acuerdo con lo informado por la Oficina Sub-Regional de la OIT, se señaló que "el Convenio tiene el objetivo de establecer normas mínimas que no deberían perjudicar el goce de normas más favorables que puedan existir a nivel nacional. De acuerdo con el artículo 35, la aplicación del Convenio no debería menoscabar los derechos o ventajas más favorables garantizados a nivel nacional, incluidos aquellos garantizados a nivel nacional como consecuencia de la ratificación por un país de cualquier otro instrumento internacional de derechos humanos" 35 .

${ }^{32}$ ONU, Asamblea General, sesión N ${ }^{\circ} 61$ del 13 de septiembre de 2007 que aprueba Declaración sobre Derechos de los Pueblos Indígenas. En la Asamblea General votaron a favor 143 países, 4 en contra (Australia, Canadá, Nueva Zelanda y Estados Unidos) y hubo 11 abstenciones (Azerbaiján, Bangladesh, Bhutan, Burundi, Colombia, Georgia, Kenya, Nigeria, Rusia, Samoa y Ucrania); y 34 estados que no votaron por estar ausentes en la sesión. Para ver las posiciones de los países que concurrieron a dicha sesión ver: http://www.un.org/News/Press/docs/2007/ga10612.doc.htm.

${ }^{33}$ Consulta dirigida a don Guillermo Miranda, director Oficina Sub-Regional de la OIT el día 16 de enero de 2008 por parte del Ministro Secretario General de la Presidencia, José Antonio Viera-Gallo.

${ }^{34}$ Luis Rodríguez-Piñero, "Cuando Proceda: Vigilancia y Aplicación de los Derechos de los Pueblos Indígenas según la Declaración”, 2010, p. 347.

${ }^{35}$ BIT (Bureau International du Travail), ILO (International Labour Office), oficio ACD 5-169 de 6 de febrero de 2008. 
Según lo expresado, un derecho o ventaja que haya sido garantizado por el derecho o la costumbre del Estado no podría ser afectado en razón de la aplicación de las disposiciones del Convenio. En otras palabras, lo que se busca es que el Convenio constituya un paso hacia delante en el reconocimiento de los derechos indígenas y no un instrumento para reducir o afectar derechos que ya se encuentren reconocidos por el derecho interno.

De acuerdo a lo señalado, resultará de importancia determinar el valor jurídico que tiene esta Declaración como instrumento internacional destinado a "garantizar" derechos o ventajas, esto es, definir si constituye un instrumento legalmente vinculante, tal cual lo sostiene en general un sector minoritario de la doctrina. O por el contrario, una herramienta política o moral que sirve de guía en la consolidación de los derechos indígenas, pero que no acarrea consecuencias legales para los Estados $^{36}$.

Por su parte, en el ámbito nacional la Corporación Nacional de Desarrollo Indígena (Conadi) ha interpretado que los derechos garantizados por otros instrumentos se refieren a aquellos que pueden ser reclamados directamente en el ámbito nacional. Al respecto señaló que "si el estándar exigido por el Convenio en alguna materia es inferior al que actualmente es exigible por los pueblos indígenas de Chile en virtud de otros instrumentos vinculantes, prima este último". A continuación indica que para interpretar dicha norma con relación a la expresión "garantizados" que utiliza el artículo 35 del Convenio, debe considerarse que "el empleo de la expresión garantizados implica que existen los mecanismos para hacer exigibles directamente, y por ende, será necesario determinar el valor jurídico del instrumento en que esté contenido el derecho o ventaja" ${ }^{37}$.

De acuerdo a lo expresado, se entenderá que el Convenio está menoscabando los derechos o ventajas "garantizados" en otras disposiciones cuando éstos puedan ser exigibles directamente de acuerdo a la legislación nacional. Por el contrario, estimamos que no podría concurrir tal menoscabo con relación al reconocimiento de derechos o ventajas en un instrumento internacional que impliquen aspiraciones

36 Veáse nota 34, supra, p. 337. El autor desarrolla en extenso las posiciones con relación al carácter vinculante o no de la Declaración.

37 Conadi, "Implementación del Convenio N¹69 de la OIT", Segunda Parte, pp. 95 y 96 . Las cursivas son nuestras. 
políticas o morales, pero cuya naturaleza consista en recomendaciones no exigibles jurídicamente, como sería el caso de la Declaración sobre Derechos de los Pueblos Indígenas.

\section{DERECHO DE CONSULTA FRENTE A MEDIDAS LEGISLATIVAS Y ADMINISTRATIVAS}

El artículo $6 \mathrm{~N}^{\circ} 1$ a) del Convenio señala que "Al aplicar las disposiciones del presente Convenio, los gobiernos deberán: a) consultar a los pueblos indígenas, mediante procedimientos apropiados y en particular a través de sus instituciones representativas, cada vez que se prevean medidas legislativas o administrativas susceptibles de afectarles directamente".

El deber que se impone sobre los Estados de consultar a los pueblos indígenas afectados por una determinada medida legislativa o administrativa constituye la piedra angular o clave del Convenio. En efecto, el establecimiento de mecanismos de consulta es fundamental para garantizar la participación efectiva de los pueblos indígenas en la toma de decisiones, y constituye la base sobre la cual reposan las demás disposiciones del Convenio ${ }^{38}$.

El objetivo principal de la consulta es posibilitar que las comunidades indígenas puedan participar en los distintos niveles de la toma de decisiones, ya sea a nivel de política pública (planes y programas), legislativa (leyes) y administrativa (actos administrativos o de gobierno), en cuanto se trate de medidas que puedan afectarles directamente.

Entre los objetivos específicos que se logran alcanzar con la participación indígena podemos enunciar los siguientes:

1. Tomar conocimiento íntegro y pleno del tipo de la medida que pretende implementarse y del grado de afectación o menoscabo que pueda generar.

2. Participar en la toma de decisiones, respecto de medidas o proyectos que los afecten.

3. Valorar las ventajas y desventajas que una medida pueda generar en la comunidad, y contemplar la posibilidad de pronunciarse informadamente sobre la viabilidad de la ejecución de la medida.

${ }^{38}$ OIT, Departamento de Normas Internacionales del Trabajo, Una Guía sobre el Convenio $N^{\circ} 169$ OIT, 2009. 
4. La consulta permite aprovechar la capacidad local de las comunidades en el diseño, desarrollo e implementación de una medida, por lo que no sólo implica el derecho a reaccionar frente a una medida, sino más generalmente a proponer sus puntos de vista y a que éstos sean considerados ${ }^{39}$.

5. Permite garantizar que no se afecte la subsistencia del grupo, tanto en su dimensión social como cultural (preservar la integridad étnica, social, económica y cultural).

6. Permite reducir la discrecionalidad administrativa en la calificación de la afectación de las comunidades, por cuanto existirán mejores antecedentes para evaluar la naturaleza y magnitud de la afectación.

Por su parte, el número 2 del artículo 6 especifica que "Las consultas llevadas a cabo en aplicación de este Convenio deberán ejecutarse de buena fe y de una manera apropiada a las circunstancias, con la finalidad de llegar a un acuerdo o lograr el consentimiento acerca de las medidas propuestas".

Con relación a los estándares a que deben sujetarse los procesos de consulta, el artículo 6 (2) del Convenio establece que las consultas deben efectuarse de buena fe y de una manera apropiada a las circunstancias. Lo anterior supone que la información debe ser íntegra y suministrada de manera apropiada, de forma que pueda ser comprendida por los pueblos indígenas. Por otro lado, los procesos de consulta deben realizarse con las organizaciones que sean genuinamente representativas para tomar decisiones en nombre de las comunidades que representan ${ }^{40}$.

${ }^{39}$ Brian Furze, "Institution Building and Community Consultation”, 1996, p. 102. Sobre el rol que el "conocimiento tradicional" de las comunidades juega en el desarrollo económico, social y cultural, véase Martin Khor, Intellectual Property, Biodiversity and Sustainable Development, Resolving the Difficult Issues, 2002, capítulo 2, p. 15.

${ }^{40}$ OIT, Convenio $N^{o} 169$ sobre Pueblos Indigenas y Tribales: Un Manual. Proyecto para Promover la Política de la OIT sobre Pueblos Indígenas y Tribales, 2003 (citado en adelante como Manual). Esta guía señala los criterios de cómo debe ejecutarse el derecho de consulta. Al respecto, se señala que éste debe realizarse en las siguientes condiciones: “a) De buena fe, respetando los intereses, valores y necesidades de la otra parte. El proceso de consulta debe ser específico a cada circunstancia y a las características especiales de un determinado grupo o comunidad. De tal manera que, por ejemplo, una reunión con ancianos de una aldea mantenida sin interpretación en una lengua que no les sea familiar, como puede resultar el idioma oficial del país (inglés, español, etc.), no puede considerarse como una verdadera consulta. b) Respetando el principio de representatividad lo cual es un componente esencial de la obligación de consulta. [...] Pudiera ser difícil en muchas circunstancias determinar quién representa una comunidad en particular. Sin embargo, si no se desarrolla un proceso de consulta adecuado con las instituciones u organizaciones indígenas y tribales verdaderamente representativas de las comunidades afectadas, la consulta encaminada no cumpliría con los requisitos del Convenio", p. 15. 


\section{APLICACIÓN DEL DERECHO DE CONSULTA POR PARTE DE LOS TRIBUNALES}

Como anteriormente señalamos, el deber general de consulta del artículo $6 \mathrm{~N}^{\circ} 1$ del Convenio relativo a medidas legislativas y administrativas que sean susceptibles de afectar directamente a las comunidades, fue declarado por el TC como una norma autoejecutable, es decir, que puede hacerse exigible directamente ante los tribunales de justicia en caso de incumplimiento.

Lo anterior explica que en la mayoría de los fallos emitidos por la Corte Suprema y por las Cortes de Apelaciones del país a partir de la vigencia del Convenio se ha invocado como fundamento de los recursos de protección para solicitar la revocación de los actos administrativos (resoluciones de calificación ambiental y decretos), el hecho de haberse omitido el trámite de consulta indígena.

A continuación se analizarán las principales implicancias de los fallos de la Corte Suprema que han permitido ir construyendo una línea interpretativa de cómo debe implementarse en Chile el derecho de consulta indígena.

\section{VIII.1. Recurso de protección por corta ilegal de bosque nativo y afectación de menokos ${ }^{41}$}

\section{a. Antecedentes}

La machi Francisca Linconao Huircapán, domiciliada en el sector Rehue de la IX Región, interpuso un recurso de protección en contra de la Sociedad Palermo Limitada que realizó una corta de árboles y arbustos nativos, alegando la vulneración de su derecho a vivir en un medio libre de contaminación establecido en la garantía constitucional del artículo $19 \mathrm{~N}^{\circ} 8$ de la Constitución Política de la República. Funda su alegación en que esta corta ilegal de árboles y arbustos nativos se realizó en infracción del artículo $5 \mathrm{~N}^{\circ} 1$ de la Ley de Bosques, que prohíbe la corta de tales especies en lugares situados a menos de 400 metros sobre los manantiales que nazcan en los cerros y los situados a menos

${ }^{41}$ Exma. Corte Suprema, sentencia de fecha 30 de noviembre de 2009, recurso de Protección Rol N ${ }^{\circ}$ 7287/2009 caratulado Francisca Linconao Huircapán con Sociedad Palermo Limitada, que confirmó la sentencia de fecha 16 de septiembre de 2009, de la Iltma. Corte de Apelaciones de Temuco. 
de 200 metros de sus orillas desde el punto en que la vertiente tenga su origen hasta aquel en que llegue al plano.

La situación se veía agravada, además, por la eventual destrucción de bosques ancestrales y la contaminación de las aguas de manantiales y vertientes denominados "menokos", de carácter sagrado en la etnia mapuche y de gran relevancia, pues en sus alrededores las machis obtienen las plantas medicinales que se utilizan en los procesos de sanación de su medicina tradicional.

El recurso fue acogido por la Corte de Apelaciones de Temuco y confirmado por la Corte Suprema.

\section{b. Implicancias}

La sentencia de la Corte de Apelaciones de Temuco, dictada un día después de la entrada en vigencia del Convenio, conlleva el hito de ser el primer fallo que aplicó entre sus considerandos las normas de dicho Convenio. En efecto, entre los considerandos para acoger el recurso se citó la aplicación del artículo $4 \mathrm{~N}^{\circ} 1$ referido al deber de los Estados de adoptar las medidas especiales que se precisen para salvaguardar las personas, las instituciones, los bienes, el trabajo, las culturas y el medio ambiente de los pueblos interesados; así como el artículo 5, referido al deber de los Estados de reconocer y proteger los valores y prácticas sociales, culturales, religiosas y espirituales propias de los pueblos originarios. En el mismo sentido, se cita también el artículo 8 que obliga al Estado al aplicar la legislación nacional a tomar en cuenta sus costumbres o su derecho consuetudinario. Finalmente, la Corte también hizo aplicable el artículo 13 del Convenio referido a los derechos sobre las tierras y territorios indígenas, en el sentido de que este último comprende el hábitat que ocupan o utilizan de alguna manera.

Adicionalmente, los considerandos del fallo de la Corte de Apelaciones de Temuco se extienden ampliamente en citar doctrina nacional e internacional con el objeto de justificar un significado amplio del concepto de medio ambiente libre de contaminación, incorporando la variable sociocultural, de manera tal que la etnia mapuche de la recurrente y la valoración de la afectación de bosques ancestrales y manantiales sagrados por parte de la recurrida deban incidir necesariamente en la estimación de que se habría vulnerado la garantía constitucional dispuesta en el artículo $19 \mathrm{~N}^{\circ} 8$ de la Constitución Política de la República. 
Más aún, el fallo desarrolla el argumento relativo a la naturaleza de derechos humanos de la cual estaría revestido el Convenio, de manera de justificar una aplicación directa de su normativa, a pesar de su carácter programático establecido por el Tribunal Constitucional al cual hemos hecho referencia. Además, el fallo postularía que esta misma naturaleza implicaría una característica supralegal de las normas del Convenio respecto a la normativa nacional, en concordancia con lo dispuesto por el artículo 27 de la Convención de Viena sobre Derecho de los Tratados.

A pesar de que el fallo de la Exma. Corte Suprema confirma lo resuelto por la Corte de Apelaciones, se puede concluir que el recurso fue acogido, más que por las argumentaciones doctrinarias de sus considerandos y por la procedencia étnica de la recurrente, por la constatación de una concreta infracción a la normativa forestal vigente en el país desde hace décadas. En efecto, en dicha sentencia confirmatoria, se consignó "que el Ministro señor Pierry y la Ministra señora Araneda si bien concurren a confirmar la sentencia en alzada, estuvieron por eliminar todos sus fundamentos, a excepción del primero; y teniendo únicamente presente el mérito de los documentos de fojas 101 a 109 de los que aparece que la Corporación Nacional Forestal dispuso la paralización de labores de acuerdo con la legislación forestal".

Cabe consignar que el considerando primero de la sentencia de la Corte de Temuco es aquel que justamente se refería a la infracción a la Ley de Bosques y Ley de Bosque Nativo y Fomento Forestal.

Sin perjuicio de que en este fallo no aplica al menos directamente el Convenio, no puede dejar de soslayarse que el considerando primero que sirve de fundamento para acoger el recurso de protección, hace referencia implícita a una noción amplia de medio ambiente libre de contaminación que no sólo se encontraría integrada por los aspectos naturales del entorno, sino también por la existencia de los componentes socioculturales, como son aquellos vinculados a la utilización ancestral de bosques y la posible contaminación de menokos o manantiales que son precisamente utilizados por las comunidades indígenas colindantes para la recolección de hierbas con fines de sanación.

En ese sentido, la Corte Suprema junto con constatar la ilegalidad de la corta por infringir la Ley de Bosques, estima que la comunidad indígena colindante tiene el carácter de interesado al verse 
afectada en su derecho a vivir en un medio libre de contaminación, precisamente por la existencia de bosques ancestrales y menokos ${ }^{42}$.

\section{VIII.2. Solicitud de regularización de derechos de aprovechamiento de aguas de la Comunidad Indígena Aimara de Chusmiza y Usmagama $^{43}$}

\section{a. Antecedentes}

El día 25 de noviembre de 2009, la Corte Suprema rechazó un recurso de casación que buscaba dejar sin efecto una sentencia de la Corte de Apelaciones de Iquique, que había dado lugar a una solicitud de regularización de 9 1/s de derechos de aguas a favor de la comunidad indígena Aimara Chusmiza y Usmagama.

En efecto, dicha comunidad había recurrido al procedimiento de regularización de aguas contemplado en el artículo 2 transitorio inciso segundo del Código de Aguas, para lo cual tuvo que acreditar ante la Dirección General de Aguas que realizaba un uso ininterrumpido por más de cinco años, sin mediar violencia o clandestinidad y sin reconocer dominio ajeno.

${ }^{42}$ La Corte Suprema venía sosteniendo una posición bastante restringida acerca del alcance de la noción de medio ambiente, vinculando a la idea de "entorno natural". Por ejemplo en Stutzin, Miguel y otros con Corema X Región, CS. 23 de septiembre de 1998 , lo define como "todo lo que naturalmente nos rodea y que permite el desarrollo de la vida y tanto se refiere a la atmósfera como a la tierra y sus aguas, a la flora y a fauna, todo lo cual conforma la naturaleza con su sistema ecológico de equilibrio entre los organismos y el medio en que viven". En el mismo sentido Guido Guirardi, y otros con Corema XII Región, CS de 19 de marzo de 1997 (caso Empresa Forestal Trillium Ltda, Proyecto Río Cóndor), lo define como al "mantenimiento de las condiciones originales de los recursos naturales, reduciendo al mínimo la intervención humana" (considerando duodécimo). En el mismo sentido Verónica Sáez Marín, recurso de inaplicabilidad - 216-2001. Rol 862-2000 RDJ Tomo XCVIII Sección V. p. 105 y sig. abril-junio 2001, se señala "Que, como lo ha dicho esta Corte, el 'medio ambiente', el 'patrimonio ambiental' y 'la preservación de la naturaleza", conceptos a los que la Constitución Política de la República hace alusión en diversos preceptos, y que está llamada a asegurar y proteger, comprenden todo lo que naturalmente nos rodea permitiendo el desarrollo de la vida; y tanto se refieren a la atmósfera, como a la tierra y sus aguas, a la flora y fauna, y a todo lo que conforma la naturaleza con sus sistemas ecológicos de equilibrio entre los organismos y el medio en que viven" (considerando quinto).

${ }^{43}$ Exma. Corte Suprema, sentencia de fecha 25 de noviembre de 2009, recurso de protección Rol N 2840/2008 caratulado Alejandro Papic Domínguez con Comunidad Indígena Aimara de Chusmiza y Usmagama. 
De acuerdo al criterio de la Corte, el derecho de regularización no se encontraría impedido por el hecho que las aguas estén inscritas a favor de un tercero. Lo señalado por la Corte no hace sino aplicar las disposiciones transitorias del Código de Aguas, que permiten la regularización contra título inscrito, siempre que se acredite un uso ininterrumpido, sin violencia ni clandestinidad de dichas aguas

Lo resuelto por la Corte Suprema viene a confirmar una jurisprudencia anterior (Comunidad Atacameña de Toconce con Essam S.A de 2004, Rol N ${ }^{\circ}$ 986-2003), por el cual se establece que la Constitución Política no sólo protege los derechos "constituidos" por la autoridad, sino también los "reconocidos" en conformidad con la ley, entre los cuales se cuentan los usos consuetudinarios de aguas reconocidos a favor de comunidades indígenas aimaras y atacameñas.

\section{b. Implicancias}

La Corte parte de la base que los derechos que se regularizan corresponden a derechos ancestrales que los miembros de la comunidad utilizan desde tiempos inmemoriales, habiendo efectuado un uso ininterrumpido de las aguas que se requieren normalizar para el consumo humano, animal y de riego, por lo que los derechos reconocidos a dicha comunidad son anteriores a cualquier acto de constitución originaria realizados por la autoridad a favor de terceros (considerando quinto).

A pesar de que la presunción de dominio a favor de la comunidad que contiene el artículo 64 de la Ley Indígena $\mathrm{N}^{\circ} 19.253$ se refiere exclusivamente a las aguas que se encuentran en "terrenos de la comunidad", la Corte mediante una interpretación finalista, esto es, con el objetivo de proteger y promover el desarrollo de los indígenas y de asegurar el abastecimiento de agua para dicha comunidad, establece una interpretación extensiva del artículo 64, en el sentido de que la presunción de dominio de las aguas que se encuentren en "terrenos de la comunidad" es aplicable también a las aguas situadas en terrenos que no pertenezcan a la comunidad por estar inscritos a nombre de un tercero, pero respecto de las cuales se ha hecho una "utilización ancestral" por parte de dichas comunidades (considerando séptimo).

Para arribar a esta conclusión, se consideran dos elementos: (i) el deber que pesa sobre el Estado de respetar, proteger y promover a los indígenas, sus culturas y tierras, lo que comprende la protección de 
las aguas indígenas con el objeto de evitar el despoblamiento de dichas comunidades, asegurando su abastecimiento; y (ii) la aplicación del concepto de "territorio" que establece el Convenio, que comprende el hábitat que los pueblos ocupan o utilizan de alguna manera (artículo 13 $\mathrm{N}^{\circ} 2$ Convenio).

De acuerdo a lo expresado por la Corte, la presunción de dominio de las aguas que establece el artículo 64 debiera interpretarse de manera coherente con la finalidad de protección de las comunidades, de manera que esta presunción no sólo debe comprender a las "tierras" que pudieran pertenecer a la comunidad, sino más ampliamente a las tierras respecto de las cuales se haga un uso tradicional (territorio).

De acuerdo a esta interpretación, se presumirían como bienes de propiedad de la comunidad no sólo las aguas que se encuentran en terrenos de ésta, sino también las aguas que se encuentren en terrenos de terceros, respecto de los cuales se hace un uso tradicional o ancestral (territorio).

Se estima que la solución dada por la Corte es correcta desde el punto de vista de su decisión, por cuanto es concordante con lo dispuesto en el Código de Aguas. En efecto, el artículo 2 transitorio no distingue si la regularización de las aguas respecto de las cuales se reclama su uso ininterrumpido se encuentra localizada ya sea en terrenos del solicitante o de terceros. Sin embargo, creemos que la aplicación de la presunción de dominio del artículo 64 como fundamento para justificar dicha regularización es improcedente.

En primer lugar, debido a que el artículo 64 de la Ley Indígena constituye una norma excepcional al régimen legal de aguas, por cuanto presume como dueño de las mismas al dueño del terreno, circunstancia que no se da con el resto de la comunidad nacional, en que las aguas son bienes nacionales de uso público. Por lo tanto, al ser una norma de aplicación excepcional debiera aplicarse restrictivamente, en el sentido que se refiere únicamente a los terrenos de propiedad de la comunidad.

En segundo lugar, por cuanto la presunción de propiedad de las aguas del artículo 64 de la Ley Indígena contempla expresamente como limitación los derechos que terceros hayan inscrito de conformidad al Código de Aguas. De acuerdo a lo señalado, esta presunción no podría ser utilizada para regularizar el uso de las aguas, ya que ésta debe respetar el dominio de terceros, circunstancia que precisamente no se da con 
la regularización, ya que la misma procede contra derechos de aprovechamiento de aguas inscritos.

Por la vía de aplicar la interpretación de la Corte Suprema haciendo extensiva la presunción de dominio respecto de terrenos de terceros, se estaría alterando el peso de la prueba, por cuanto se les presumiría dueños de las aguas y por tanto poseedores de buena fe, limitándose a tener que acreditar el transcurso del tiempo de cinco años.

En nuestra opinión, lo resuelto por la Corte Suprema es coherente con el régimen de regularización de aguas. Sin embargo, esta solución debió haberse obtenido por la vía de la sola aplicación del artículo 2 transitorio del Código de Aguas, por cuanto dicha disposición permite regularizar las aguas, situación que puede darse respecto de aguas localizadas en terrenos propios o ajenos, ya que el Código de Aguas no distingue al respecto.

Cabe consignar que aunque la Corte hizo aplicación del concepto de "territorio indígena", lo hizo en forma coherente con la exigencia del Convenio que establece que corresponde al hábitat que las comunidades “ocupan o utilizan”, según el artículo 13 (2) del Convenio. Como consecuencia de ello, la Corte tuvo como un hecho no controvertido que el uso de las aguas se habría hecho de manera "ininterrumpida" desde períodos precolombinos hasta nuestros días, lo que se manifiesta por la existencia de socavones, estanques de acumulación, terrazas de cultivos, canales y el mismo asentamiento humano. Lo anterior es plenamente concordante con los requisitos del artículo 2 transitorio que exige utilización ininterrumpida.

De acuerdo a este criterio, no bastaría con señalar que ha existido una utilización histórica de aquellos territorios, como plantean algunas organizaciones de defensa indígena, sino que se requiere una conexión entre ese uso inmemorial con la actualidad. De tal forma que si no se acredita ese uso ininterrumpido en el uso de las aguas, la sola existencia de las mismas en terrenos o territorios indígenas no sería suficiente para solicitar la regularización. Ello, por cuanto el reconocimiento de derechos sobre los recursos naturales supone un uso tradicional inmemorial amparado por un uso actual o a lo menos reciente; sobre esta materia nos detendremos al analizar los derechos que el Convenio reconoce para reclamar la propiedad y posesión de tierras que tradicionalmente ocupan las comunidades. 


\title{
VIII.3. Recurso de protección contra una resolución de calificación ambiental de un proyecto de piscicultura ${ }^{44}$
}

\author{
a. Antecedentes
}

Representantes de la comunidad indígena Palguín Bajo y comunidad indígena Antonio Huenuñanco, de la comuna de Pucón, Región de la Araucanía, interpusieron un recurso de protección en contra de la Corema Región de la Araucanía (hoy Comisión de Evaluación), por haber pronunciado una Resolución de Calificación Ambiental (RCA), calificando favorablemente una Declaración de Impacto Ambiental (DIA) de un proyecto de piscicultura. La Corte de Apelaciones de Temuco resolvió anular dicha RCA por no haberse realizado previamente la consulta indígena que contempla el artículo 6 del Convenio. Sin embargo, la Corte Suprema procedió a revocar el fallo de la Corte de Apelaciones mediante el acuerdo unánime de sus miembros.

\section{b. Implicancias}

La Corte Suprema estimó que la consulta indígena es procedente, siempre que se trate de medidas legislativas o administrativas que sean susceptibles de afectar directamente a la población protegida. En este sentido, la Corte estimó que la consulta es procedente cuando se produzca "afectación" en los términos que se indica, sin ser relevante si la medida constituye un acto administrativo de efectos generales o particulares, como es en este último caso una RCA. Con lo anterior se pondría término a la discusión en cuanto a que sólo las medidas administrativas generales, tales como decretos o reglamentos, deben ser consultadas ${ }^{45}$.

Para la Corte Suprema, la forma en que se realice la evaluación ambiental, esto es, por medio de una DIA o un Estudio de Impacto Ambiental (EIA), es el elemento determinante para definir la procedencia de la consulta indígena, tratándose de proyectos sometidos al Sistema de Evaluación de Impacto Ambiental (SEIA). Esto obedece a que la

${ }^{44}$ Exma. Corte Suprema, sentencia de fecha 17 de mayo de 2010, recurso de protección Rol N ${ }^{\circ}$ 1525/2010 caratulado Puelman Nanco, Mariano y otro contra Comisión Regional del Medio Ambiente de la Araucanía.

${ }^{45}$ Esta posición fue refrendada en el fallo de 14 de octubre de 2010 de la Corte Suprema en el caso de la DIA "Sistema de Conducción y Descarga al Mar de Efluentes Tratados de Celulosa Arauco", según se pasará a exponer más adelante. 
lógica de la Corte es que debe haber consulta indígena cuando se producen los efectos, circunstancias o características del artículo 11 letra c) de la Ley $\mathrm{N}^{\circ} 19.300$, esto es, reasentamiento de comunidades humanas o alteración significativa de los sistemas de vida y costumbres de grupos humanos.

Por lo tanto, cuando un proyecto identifica el artículo 11 letra c) como causal para hacer exigible un EIA, no sólo deberá ingresar su proyecto por medio de este instrumento, sino que además deberá asegurarse que se realice por parte del Estado un procedimiento de consulta previo de las comunidades indígenas afectadas.

Por el contrario, es posible concluir que si un proyecto ingresa al SEIA por medio de una DIA, no requeriría dar cumplimiento a la consulta indígena, por cuanto dicho proyecto no genera por su naturaleza o magnitud estos efectos, circunstancias o características. De acuerdo a lo argumentado por la Corte, si un proyecto ingresado como DIA durante la evaluación ambiental se determina que genera esta afectación, entonces "deviene inexorablemente en el rechazo de la declaración de impacto ambiental presentada por el titular y su sustitución por un estudio de impacto ambiental" (considerando décimo primero).

En definitiva, en concepto de la Corte Suprema, el elemento clave para definir la procedencia de la consulta indígena del Convenio es que se produzca "afectación", la cual se encuentra definida en el artículo 11 letra c) de la Ley $\mathrm{N}^{\circ} 19.300$ complementado por el artículo 8 del Reglamento del SEIA, esto es, cada vez que se genere o presente reasentamiento de comunidades humanas, o alteración significativa de los sistemas de vida y costumbres de grupos humanos, caso en cual se requerirá la presentación de un EIA.

La Corte Suprema también deja asentada una antigua jurisprudencia desarrollada tanto en sede jurisdiccional como por parte de la Contraloría General de la República, en el sentido que corresponde a la Corema (hoy Comisión de Evaluación), como órgano técnico, resolver sobre la necesidad de presentar un EIA. Ésta es una materia de vital importancia, por cuanto al órgano que le corresponde la definición sobre cuándo se entiende que existe afectación tratándose de proyectos sometidos al SEIA, es al órgano técnico competente (Corema y órganos con competencia ambiental), y no a los tribunales de justicia. Por lo anterior, si el Informe Consolidado de la Evaluación y la subsecuente RCA determinan que un proyecto no genera los efectos, circunstancias 
o características del artículo 11 letra c), no correspondería a los tribunales de justicia pronunciarse de manera contraria (considerando décimo cuarto $)^{46}$.

Finalmente, la Corte Suprema pareciera validar como un procedimiento idóneo, para dar cumplimiento a los estándares de la consulta indígena del Convenio, al procedimiento de participación ciudadana que establece la Ley $\mathrm{N}^{\circ} 19.300$ a propósito de los EIA. En efecto, la Corte da a entender que la participación ciudadana en los EIA constituye una instancia plena de participación, en especial de las organizaciones ciudadanas y personas naturales afectadas (considerandos undécimo y duodécimo).

\section{VIII.4. Recurso de protección contra una resolución de calificación ambiental de un proyecto de conducción y descarga al mar de efluentes tratados ${ }^{47}$}

\section{a. Antecedentes}

Diversas comunidades indígenas mapuches de la comuna de San José de la Mariquina, en la región de Los Ríos, interpusieron un recurso de protección en contra de la Corema región de Los Ríos por haber pronunciado una RCA calificando favorablemente un EIA del proyecto "Sistema de Conducción y Descarga al Mar de Efluentes Tratados de Planta Valdivia", cuyo titular es Celulosa Arauco y Constitución S.A.,

${ }^{46}$ Recientemente la Corte de Apelaciones de Concepción en un fallo de 1 de diciembre de 2010 en un recurso de protección Rol № 401/2010 interpuesto por diversas comunidades agrícolas y personas naturales contra Corema Región del Biobío por calificar ambientalmente favorable el proyecto Mini-Central Hidroeléctrica Cayupil, reclamaron que no fueron debidamente consultadas. La Corte resolvió rechazar el recurso considerando entre otros fundamentos el carácter técnico y sectorial de los pronunciamientos emitidos por los órganos del Estado. Al respecto se indicó "Particular importancia tiene la intervención de 21 órganos de la administración central y descentralizada que se pronuncian en materias propias de su competencia sobre la viabilidad del proyecto en tramitación. Se trata así de un procedimiento complejo, de carácter técnico, con intervención de variadas instituciones que aseguran una conclusión fundada, descartándose el capricho o arbitrariedad propia de una resolución sin fundamento" (considerando quinto).

${ }^{47}$ Exma. Corte Suprema, sentencia de fecha 14 de octubre de 2010, recurso de protección Rol N ${ }^{\circ}$ 4078/2010 caratulado Nahuelpán Guilitraro, representante Comunidad Indigena Villa Nahuel y otros contra Comisión Regional del Medio Ambiente Región de Los Ríos. 
por cuanto no se habría dado cumplimiento al trámite de consulta indígena del Convenio.

La Corte de Apelaciones de Valdivia procedió a rechazar el recurso de protección interpuesto, para finalmente la Corte Suprema proceder a confirmar la sentencia de la Corte de Apelaciones de Valdivia. Sin embargo, cabe tener presente que los fundamentos tenidos en consideración para tener por rechazado dicho recurso fueron parcialmente diferentes de los señalados por la Corte de Apelaciones de Valdivia.

\section{b. Implicancias}

La CS realiza una aclaración sobre el sentido de la consulta indígena, señalando que no es otra cosa que el derecho que el artículo $1^{\circ} \mathrm{de}$ la Constitución Política reconoce a participar en igualdad de oportunidades en la vida nacional para lograr su mayor realización espiritual y material. En este sentido, si bien las comunidades indígenas constituyen "un grupo con una especificidad cultural que le es propia", este derecho de participación y consulta sería propio de todos los nacionales de Chile (considerando primero).

Cabe recordar que el Tribunal Constitucional se había pronunciado en el mismo sentido al analizar la naturaleza del derecho de consulta en el caso de la prospección y explotación de recursos que pertenezcan al Estado ${ }^{48}$.

La CS ratifica lo señalado por la propia OIT en el sentido de que la consulta no supone un derecho a veto (opinión vinculante), por cuanto tal como lo señaló el Tribunal Constitucional en su oportunidad, la utilización del término pueblos no deberá interpretarse en el sentido de que detentan la soberanía o su ejercicio, asignándoseles alguna potestad pública o de decisión, como sería el caso del reconocimiento a un derecho a la autodeterminación, o de veto frente a la aprobación de un proyecto.

$\mathrm{Al}$ respecto, el considerando segundo indica "Que cabe destacar a su vez que la consulta a los pueblos interesados que prevé el numeral $1^{\circ}$ del artículo 6 del Convenio tiene por finalidad arribar a un acuerdo acerca de las medidas propuestas, pero jamás dicha forma de participa-

48 Tribunal Constitucional Rol No 309 del 4 de agosto de 2000, considerando 72. Al respecto el TC concluye: "La participación a que se refiere el tratado, en esta parte, debe entenderse en el marco de lo que dispone el artículo $1^{\circ}$ de la Constitución, que consagra el deber del Estado de asegurar el derecho de las personas a participar con igualdad de oportunidades en la vida nacional". 
ción podría constituirse en una consulta popular vinculante ni afectar las atribuciones privativas de las autoridades que la Carta Fundamental determina. La soberanía, conforme lo dispuesto en el artículo $5^{\circ}$, reside esencialmente en la Nación y se ejerce a través del plebiscito y elecciones periódicas y por las autoridades que la propia Constitución establece, y ningún sector del pueblo ni individuo alguno puede atribuirse su ejercicio".

En el mismo sentido, el considerando cuarto establece "Que las normas antes transcritas demuestran que la participación consultiva contemplada en el Convenio no conlleva dotar a los pueblos indígenas de poderes o potestades públicas, sino consolidar el derecho que les asiste a ser consultados en las materias que les atañen".

La CS realiza otra afirmación, en el sentido de que el Convenio debe implementarse considerando las condiciones de cada Estado, según sus propias regulaciones (considerando sexto). En este mismo sentido, se hace referencia expresa al principio de flexibilidad que establece el artículo 34 del Convenio, que estipula que la naturaleza y alcance de las medidas que se adopten para dar efecto al Convenio deberán determinarse "teniendo en cuenta las condiciones propias de cada país" (considerando quinto).

Lo señalado por la CS vendría a indicar que los derechos que se reconocen en el Convenio no necesariamente implican la modificación del ordenamiento jurídico vigente, sino que tales derechos para implementarse deberán considerar las condiciones de cada país, lo que supone por cierto tener en cuenta las condiciones regulatorias que establece el ordenamiento jurídico vigente.

La CS resuelve en el sentido de que la participación ciudadana de la Ley $\mathrm{N}^{\circ} 19.300$ es compatible y suficiente para canalizar la consulta indígena del Convenio. Lo señalado constituye la base argumentativa para proceder al rechazo del recurso de protección. En efecto, de acuerdo al raciocinio expresado por la $\mathrm{CS}$, el deber de consulta indígena ya se encuentra incorporado en el ordenamiento jurídico vigente, específicamente en la participación ciudadana que contempla la Ley $\mathrm{N}^{\circ} 19.300$. Al respecto el considerando séptimo establece "Que conforme a estos lineamientos, forzoso es concluir que el deber general de consulta a los pueblos indígenas en lo concerniente a los procedimientos de evaluación de impacto ambiental estatuido en la Ley $\mathrm{N}^{\circ} 19.300$ y su Reglamento ya se encuentra incorporado a dicha legislación ambiental a través del 
procedimiento de participación ciudadana que los artículos 26 a 31 de la citada ley establecen".

La CS incluso llega a sostener que la participación ciudadana de la Ley $N^{\circ} 19.300$ constituye un mecanismo plenamente compatible con los estándares del principio de la buena fe y de haberse utilizado los "procedimientos adecuados" que exige el Convenio. Al respecto, el considerando noveno señala que la participación ciudadana del EIA cuyo titular es Celulosa Arauco, "cumplió con las exigencias y propósitos que el $\mathrm{N}^{\circ} 2$ del artículo 6 del Convenio les otorga a las consultas, esto es, de ejecutarse de buena fe y de una manera apropiada a las circunstancias con la finalidad de llegar a un acuerdo acerca de las medidas propuestas".

De acuerdo a lo expresado, en el criterio de la CS la consulta indígena del Convenio no sólo se encontraría desde ya regulada en la actual normativa vigente, por lo menos para los proyectos sometidos al SEIA, sino que además se otorga un respaldo a los estándares de participación que dicho procedimiento contempla, argumentándose que tal procedimiento es compatible con los estándares de consulta del Convenio, esto es, que se trata de procedimientos que se realizan de buena fe y a través de un mecanismo adecuado a las circunstancias.

Al respecto se concluye en el considerando undécimo "Que como es posible apreciar, el procedimiento de participación ciudadana en los proyectos sometidos a estudio de impacto ambiental previsto en el artículo 26 de la Ley $\mathrm{N}^{\circ} 19.300$ es el mecanismo a través del cual se lleva a efecto el deber de consulta a que obliga el Convenio $N^{\circ} 169$, cuyo texto y principios que lo informan resultan plenamente compatibles y alcanzan eficacia con la normativa ambiental vigente".

En el mismo sentido, en el considerando duodécimo se señala que la integración del Convenio al ordenamiento jurídico nacional en el caso de un proyecto sometido a evaluación ambiental mediante un EIA "ha sido claramente satisfecha por la autoridad recurrida al cumplir con las exigencias jurídicas aplicables conforme a la normativa sectorial que la rige, las cuales son enteramente conciliables con los estándares que orientan el Convenio" 49 .

${ }^{49} \mathrm{Si}$ bien hubo cuatro votos a favor de rechazar el recurso de protección, cabe destacar el voto disidente del ministro Brito, el cual es del parecer de aceptar el recurso, por cuanto en su opinión era necesario un procedimiento especial de consulta que considere elementos de análisis propios de la realidad por la que se reclama, circunstancia que no se logra con la participación general de la Ley $\mathrm{N}^{\circ} 19.300$. 
Si bien la CS confirmó la sentencia de la Corte de Apelaciones de Valdivia, en el sentido de que no era procedente acoger el recurso de protección interpuesto, la CS procedió a eliminar los considerandos undécimo, duodécimo, décimo sexto, décimo séptimo y décimo octavo en el fallo de la Corte de Apelaciones.

Tener en consideración esta circunstancia es relevante, por cuanto la Corte de Apelaciones de Valdivia había estimado como un argumento para rechazar el recurso de protección el hecho de que el Reglamento de Consulta Indígena contendido en el DS N ${ }^{\circ} 124 / 2009$ del Mideplan sólo hacía exigible la consulta indígena de acuerdo al artículo 15 párrafo segundo tratándose de "las políticas, planes y programas".

Lo anterior llevó a la Corte de Apelaciones de Valdivia a señalar que los actos administrativos particulares, como es el caso de una RCA, no debieran ser consultados ${ }^{50}$. En este sentido, si bien la Corte Suprema confirma el fallo de la Corte de Apelaciones de Valdivia, rechaza el fundamento invocado por la Corte de Apelaciones, lo que nos lleva a concluir que, en opinión del máximo tribunal, los actos administrativos de efectos generales o particulares quedan incorporados dentro de la denominación genérica de "medidas administrativas" a que hace referencia el artículo 6 del Convenio, por lo que ambos deben ser consultados cuando afecten directamente a las comunidades indígenas.

Creemos que lo resuelto por la CS no es más que la consecuencia de lo señalado por el mismo tribunal en el caso Palguín al que hemos hecho referencia, por cuanto de acuerdo con el Tribunal Supremo el elemento clave para definir la procedencia de la consulta indígena no es el tipo o naturaleza de acto administrativo (general o particular), sino la "afectación" que éste produce. En efecto, de acuerdo al máximo tribunal, tal afectación se producirá cuando se generen o presenten los efectos, circunstancias o características del artículo 11 (c) de la Ley $\mathrm{N}^{\circ} 19.300$ complementado por el artículo 8 del Reglamento del SEIA,

${ }^{50} \mathrm{Al}$ respecto la Corte de Apelaciones de Valdivia señaló textualmente: "Como se observa, la consulta es necesaria en el caso que la administración del Estado sostenga nuevas políticas (medioambientales u otras), nuevos planes y programas que afecten directamente a los pueblos indígenas, circunstancias del todo ajenas al acto administrativo impugnado, que es el resultado de un Estudio de Impacto Ambiental" (considerando duodécimo), recurso de protección Rol № 148/2010 caratulado Nahuelpán Guilitraro, Representante Comunidad Indígena Villa Nahuel y otros contra Comisión Regional del Medio Ambiente Región de Los Ríos. 
esto es, relocalización o alteración en los sistemas de vida y costumbres de las comunidades indígenas, situación que únicamente se produce en los casos de los EIA.

\subsection{Resumen de la jurisprudencia de la Corte Suprema}

Del análisis coherente y sistemático de los fallos pronunciados en relación con el deber de consulta indígena establecido en el Convenio, es posible extraer las siguientes conclusiones que nos permiten analizar la forma en que nuestro máximo tribunal entiende que debe ser implementada la consulta indígena, a saber:

- La participación prevista en el Convenio no constituye una consulta popular vinculante ni puede afectar las atribuciones privativas de las autoridades que la Carta Fundamental determina.

- La consulta procede cuando hay "afectación" de pueblos indígenas, sin importar si se trata de una medida administrativa de carácter general o particular.

- $\quad$ En el caso de proyectos sometidos al SEIA, se produce afectación de los pueblos indígenas cuando se generan los efectos, circunstancias o características mencionadas en el Artículo 11 (c) de la Ley $\mathrm{N}^{\circ} 19.300$, esto es, si el proyecto o actividad implica reasentamiento de comunidades humanas, o alteración significativa de los sistemas de vida y costumbres de grupos humanos.

- Para el caso de producirse dicha afectación, tales proyectos o actividades deberán ser evaluados a través de un EIA, procedimiento que de acuerdo a la Ley $\mathrm{N}^{\circ} 19.300$ contempla una instancia de participación ciudadana.

- $\quad$ La instancia de participación ciudadana de la Ley $\mathrm{N}^{0} 19.300$ es adecuada y plenamente compatible con los estándares de la consulta indígena que establece el Convenio.

\section{APLICACIÓN DEL DERECHO DE CONSULTA POR LOS ÓRGANOS DE LA ADMINISTRACIÓN DEL ESTADO}

Desde la entrada en vigencia del Convenio es posible constatar una aplicación heterogénea de la consulta indígena, en especial en lo relativo al responsable de efectuar dicha consulta, su procedimiento y 
procedencia. Esto se refleja en las distintas interpretaciones de los órganos de la administración del Estado respecto a la forma en que debiera implementarse dicho Convenio, lo que ha significado en muchos casos exceder el sentido y espíritu del mismo.

\section{IX.1. Implementación durante el SEIA}

Si bien el derecho de consulta constituye un deber para el Estado, diversos órganos con competencia ambiental al evaluar proyectos sometidos al SEIA han requerido a los titulares de proyectos la realización de acciones de consulta hacia las comunidades, traspasando de esta forma la obligación hacia los privados ${ }^{51}$. En otras circunstancias, el propio organismo encargado de los asuntos indígenas ha llegado a exigir a los titulares de proyectos la "autorización" de la comunidad indígena como condición para ejecutar los proyectos ${ }^{52}$.

Con relación al procedimiento con el que debe realizarse la consulta indígena, algunos órganos del Estado han calificado como insuficiente el proceso de participación ciudadana contemplado por la Ley $\mathrm{N}^{\circ} 19.300$ para los Estudios de Impacto Ambiental, ya que estiman que este procedimiento no daría respuesta satisfactoria a lo estipulado en el artículo 6 del Convenio ${ }^{53}$.

Una de las principales problemáticas en relación con la procedencia de la consulta indígena se encuentra dada por la localización de

${ }^{51}$ Proyecto DIA “Estación de Transferencia de Residuos Sólidos Lanco-Panguipulli”, de la I. Municipalidad de Lanco, oficio del director de la Conadi, Región de Los Ríos No 128 de 24 de marzo de 2010 que le exigió al titular implementar un plan estratégico de comunicación durante la evaluación ambiental.

52 Proyecto DIA “Proyecto Eólico Quillagua de 100 MW" de Ingeniería Seawind Sudamérica Ltda., oficio de la Conadi San Pedro de Atacama, Región de Antofagasta $\mathrm{N}^{\circ} 415$ de 16 de diciembre de 2008. En el mismo sentido tratándose de sondajes que recaen sobre terrenos en proceso de saneamiento, proyecto DIA "Programas de Exploración Turi” de BHP Chile Inc., oficio Conadi San Pedro de Atacama, Región de Antofagasta $\mathrm{N}^{\circ} 0054$ de 13 de febrero de 2009.

53 Proyecto EIA "Modificaciones y Mejoramiento del Sistema de Pozas de Evaporación Solar en el Salar de Atacama" de Sociedad Chilena del Litio, oficio de la Seremi de Mideplan Región de Antofagasta N 709 de 21 de octubre de 2009. En el mismo sentido el proyecto DIA "Prospección Minera Lobo Marte Etapa II" de Minera Santa Rosa SCM, oficio de Conadi Región de Atacama $\mathrm{N}^{\circ} 107$ de 7 de junio de 2010. Este último oficio da a entender que la consulta indígena debiera correr por un carril separado de la participación ciudadana de la Ley $\mathrm{N}^{\circ}$ 19.300. En efecto, la Conadi concluye: "que sin perjuicio del proceso de consulta previa, del mismo análisis del proyecto, se puede colegir que la formulación del proyecto [...] justifica la presentación de un EIA". 
proyectos o actividades en Áreas de Desarrollo Indígena (ADI). Así por ejemplo, se ha indicado que por el solo hecho de efectuarse el proyecto dentro de un ADI, se hace necesario establecer un proceso de consulta indígena, sin hacer referencia a la significación o magnitud de los impactos que pudiera generar el proyecto ${ }^{54}$.

De acuerdo a esta interpretación, la mera localización de un proyecto en un área con población indígena sería causal suficiente para hacer exigible la consulta indígena. Sin embargo, si se considera que de acuerdo al artículo 6 del Convenio el elemento que define la procedencia de la consulta es la "afectación directa" que una determinada medida puede producir en las comunidades, el sólo hecho de la localización de un proyecto en áreas con presencia indígena no significa automáticamente que se produzca su afectación.

En efecto, un proyecto en áreas con presencia indígena no necesariamente debe significar un impacto negativo para dichas comunidades, ya que puede acarrear un beneficio para las mismas. Sobre este punto, la Corte de Apelaciones de Temuco rechazó un recurso de protección interpuesto por una comunidad indígena mapuche que se oponía a la construcción de la ruta Temuco-Labranza, por cuanto afectaría una obra de agua potable rural de propiedad de la comunidad. Al respecto la Corte estimó que por el contrario el proyecto traería un mejor y mayor desarrollo para dicha comunidad ${ }^{55}$.

Por otro lado, la mera localización en áreas con presencia indígena no necesariamente significa que se producirá afectación, ya sea en razón de la distancia en que habitan o desarrollan sus actividades, quedando fuera del área de influencia de los proyectos, o en razón de las medidas de mitigación que se propongan lo que permite evitar, impedir

${ }^{54}$ Proyecto DIA “Ampliación y Mejoramiento Aeropuerto El Loa Calama II Región de Antofagasta" del Ministerio de Obras Públicas, oficio de la Seremi de Mideplan Región de Antofagasta $N^{\circ} 596$ de 13 de octubre de 2009.

55 Ilust. Corte de Apelaciones de Temuco, sentencia de 27 de septiembre de 2010, recurso de protección Rol N 1155-2010 caratulado Comunidad Indígena Mapuche Hueche Huenulaf contra el Ministerio de Obras Públicas. La Corte rechazó el recurso considerando que el desarrollo del proyecto no implicaba afectación, por cuanto en esa etapa de proyecto no presenta consecuencias negativas ni para la comunidad ni para los integrantes de la misma individualmente considerados, señalando expresamente que "no se ha acreditado alguna afectación a sus derechos como pueblo indígena", agregando que "por el contrario, la construcción de ese camino traerá, a no dudarlo, un mejor y mayor desarrollo económico, social, cultural y de acercamiento a los sistemas de salud y de conectividad $[\ldots]$ ". (considerando décimo quinto). 
o disminuir la ocurrencia de impactos significativos directos en las comunidades.

De acuerdo a lo expresado, la localización de un proyecto en un área con presencia indígena constituye un elemento adicional o complementario a considerar, pero no puede convertirse en el elemento esencial y único que determine la procedencia de la consulta indígena. Lo anterior, por cuanto el procedimiento de consulta y participación requiere de la existencia de "pueblos interesados", esto es, aquellos que tienen un interés comprometido que puede ser afectado por una determinada medida, según disponen numerosos artículos del Convenio (art. 6 , art. 7 , art. 8 , art. 14 , art. 15 , art. 16 , etc. $)^{56}$.

La fórmula empleada por el Ejecutivo en el Reglamento de Consulta Indígena (DS 124/2009 de Mideplan) de hacer procedente la consulta respecto de proyectos de inversión que se ejecuten en Áreas de Desarrollo Indígena (ADI) y tierras indígenas ${ }^{57}$, debe ser aplicada de manera coherente con el Convenio, en el sentido de que la localización de un proyecto en áreas de desarrollo indígena no es causal automática de la consulta indígena, sino cuando se acredite que se produce afectación directa de las comunidades.

Considerando que las ADI en algunas regiones del país representan territorios relativamente extensos, es preciso establecer criterios que permitan distinguir en qué casos se aplica la consulta indígena a aquellos proyectos que se ejecutan dentro de ellas, para lo cual se proponen los siguientes criterios de diferenciación:

(i) Criterio de la afectación: la aplicación de la consulta indígena corresponderá en el caso de comunidades que se vean afectadas por la implementación de la medida. De esta manera, no basta con que existan comunidades habitando dentro de un ADI, sino que se requiere demostrar que la medida altera sus formas de vida tradicionales.

(ii) Criterio del área de influencia: el límite territorial de la afectación se determinará con relación al área de influencia del proyecto, de

${ }^{56}$ El Manual del Convenio de la OIT del año 2003 define a los pueblos interesados como "los que se verán afectados por una determinada medida", es decir, aquellos que recibirán algún impacto negativo en su calidad de indígenas.

${ }^{57}$ El artículo $5^{\circ}$ del DS 124/2009 de Mideplan que establece el Reglamento de Consulta Indígena se refiere a la consulta de las comunidades indígenas en caso de "proyectos de inversión en las tierras indígenas o áreas de desarrollo indígena establecidas en la Ley No 19.253 ". 
manera que la consulta será aplicable a las comunidades localizadas en una ADI que se encuentre dentro del área de influencia del proyecto.

(iii) Criterio de afectación en su calidad de indígena: los pueblos indígenas son reconocidos y respetados como tales en razón de su aporte a la multiculturalidad y al hecho de conservar manifestaciones étnicas y culturales que les son propias (artículo $1^{\circ}$ de la Ley Indígena). De esta forma, la afectación de una comunidad indígena debido al desarrollo de un proyecto se determinará en relación con las manifestaciones étnicas, culturales o religiosas que les son propias. Éstos son los elementos que le dan sentido a la existencia de una protección especial para los indígenas, de manera que si un proyecto localizado próximo a una comunidad no genera efectos adversos en estos elementos étnicos o culturales, no corresponderá aplicar la consulta indígena.

La Contraloría General de la República, a propósito de la localización próxima de proyectos en áreas protegidas, ha señalado que la "mera proximidad" entre el proyecto y el área protegida no es requisito suficiente para exigir la presentación de un EIA $^{58}$. Si bien el dictamen de la Contraloría tiene por objeto clarificar la procedencia de una DIA o EIA, está poniendo en evidencia que la mera localización no supone necesariamente "afectación", sino que habrá que analizar el tipo de intervención o magnitud de los impactos y medidas propuestas para hacerse cargo de ellos.

\section{IX.2. Alcance de la expresión "cuestión indígena" que contempla la Ley Indígena}

El día 17 de diciembre de 2009, la Contraloría General de la República procedió a informar ante la Corte de Apelaciones de Santiago respecto de un recurso de protección interpuesto en su contra, por el hecho de haber tomado razón del Decreto No 192 de 2009 del Ministerio de Economía mediante el cual se otorga a una empresa de generación

${ }^{58}$ Contraloría General de la República, dictamen N ${ }^{\circ} 13.432$ de fecha 27 de marzo de 2008. El dictamen señala que "no resultaba objetable el ingreso al SEIA mediante una DIA", ya que la Ley No 19.300 "no se limita a requerir la evaluación ambiental en razón de la mera proximidad entre el proyecto o actividad respectivo y el área protegida", sino que se requiere acreditar que sea "susceptible de ser afectada por el proyecto", dada la magnitud o duración de la intervención. 
eléctrica la concesión definitiva para establecer una central hidroeléctrica en la Región de Los Lagos ${ }^{59}$.

El mencionado informe efectúa un pronunciamiento sobre los alcances del deber de consulta indígena que contempla el artículo 34 de la Ley Indígena $N^{\circ} 19.253$. Dicha disposición legal señala que los servicios de la administración del Estado, cuando traten materias que tengan ingerencia o relación con "cuestiones indígenas", deberán escuchar y considerar la opinión de las organizaciones indígenas que reconoce esta ley.

Cabe recordar que dicha norma fue reglamentada a través del Reglamento de Consulta Indígena contenido en el DS No 124/2009 de Mideplan, estableciendo los supuestos y el procedimiento en que debe realizarse la consulta indígena.

La Contraloría, ante el reclamo de no haberse efectuado la consulta indígena en forma previa al otorgamiento de la concesión eléctrica, señaló los siguientes puntos que resultan de interés para los efectos de delimitar la procedencia de la consulta indígena frente a "cuestiones indígenas".

a. Que el otorgamiento de la concesión no reviste la naturaleza de "cuestión indígena" a que alude el artículo 34 de la Ley indígena

La Contraloría señala que la tramitación de la concesión no es una materia indígena, dado lo cual no requiere ser consultada. Lo señalado podría ser aplicable no sólo a las concesiones eléctricas, sino también a las mineras, otorgamiento de derechos de aguas, constitución de servidumbres, etc., por cuanto dichos procedimientos corresponderían a materias mineras, eléctricas o de aguas, etc., pero no a cuestiones indígenas.

De acuerdo con lo expresado por la Contraloría, la procedencia de la consulta indígena dependerá de que se esté en presencia de "cuestiones indígenas", como sería el caso de planes de desarrollo para indígenas, subsidios indígenas, fijación de Áreas de Desarrollo Indígena (ADI), etc.

La Contraloría expresa que la consulta que establece el Reglamento de Consulta Indígena contenido en el DS No 124/2009 se refiere a las medidas legislativas y administrativas que sean susceptibles de

${ }^{59}$ Contraloría General de la República, dictamen N 70292 de fecha 17 de diciembre de 2009. 
afectarles directamente y que tengan su origen en algunos de los órganos de la administración del Estado señalados en el artículo 4 de dicho Reglamento, situación que no comprendería al decreto que otorga la concesión.

De acuerdo a lo señalado por Contraloría, el decreto que aprueba la concesión eléctrica y cuya toma de razón fuera cursada por el órgano contralor, no estaría comprendido dentro de las medidas legislativas y "administrativas" a que hace referencia el Reglamento de Consulta Indígena.

Lo anterior estaría recogido en la propia definición de "afectación" que contempla el Reglamento de Consulta Indígena en el artículo 7, que entiende que existe "cuando la medida legislativa o administrativa o el respectivo plan o programa de desarrollo nacional o regional, según corresponda, diga relación exclusiva con las tierras indígenas o áreas de desarrollo indígena establecidas en la ley $\mathrm{N}^{0} 19.253$, o se refiera a una mayoría significativa de comunidades, asociaciones y organizaciones indígenas determinadas o determinables".

\section{b. La oportunidad procesal de "oposición" que contempla el} procedimiento concesional constituye una instancia adecuada para reclamar de la vulneración de los derechos de los indígenas

La Contraloría señala que tanto la Conadi como los miembros de alguna comunidad indígena que estimen que la concesión vulnera sus derechos o afecta sus tierras "han tenido la oportunidad de hacer valer sus oposiciones en la tramitación del procedimiento concesional — toda vez que de la solicitud se efectúan publicaciones para que se opongan los que estimen vulnerados sus derechos - sin que éstas hayan sido planteadas".

De acuerdo a lo anterior, el órgano contralor estaría validando la suficiencia del procedimiento de oposición que contempla la actual legislación, como una instancia adecuada para que las organizaciones indígenas puedan hacer valer sus derechos. En otras palabras, la Contraloría estima que aun cuando no se hubiere efectuado una consulta especial indígena previa al otorgamiento de la concesión eléctrica, esto no infringiría la Ley Indígena ni el Reglamento de Consulta Indígena, por cuanto dicho procedimiento contempla la posibilidad de formular oposiciones. 
Lo señalado por Contraloría resulta coincidente con lo resuelto por el Tribunal Constitucional en cuanto a la necesidad de consulta previa para el desarrollo de labores mineras. En efecto, el TC señaló que el procedimiento judicial de constitución de concesiones mineras constituye una "garantía para que todos los interesados puedan ser escuchados frente a una violación de sus derechos". En este sentido, el TC es de la opinión que este derecho de consulta ya se encuentra garantizado en el actual procedimiento judicial ${ }^{60}$.

\section{REFLEXIONES PARA UNA ADECUADA IMPLEMENTACIÓN DEL CONVENIO}

\section{X.1. Derecho en relación con las tierras}

Según se ha indicado anteriormente, el Convenio reconoce a los indígenas dos derechos de distinta jerarquía o entidad. El primero relacionado con que se les reconozcan sus derechos de propiedad y posesión sobre tierras que tradicionalmente ocupan (artículo $14 \mathrm{~N}^{\circ} 1$ primera parte), y el segundo, el derecho a utilizar las tierras a las que tradicionalmente han accedido aunque no sean ocupadas exclusivamente por ellos (artículo $14 \mathrm{~N}^{\circ} 1$ segunda parte).

Cabe recordar que el Tribunal Constitucional estableció que estas disposiciones tenían el carácter de programáticas, es decir, disposiciones que reflejan declaraciones pero no son ejecutables con el solo mérito del tratado. Como consecuencia de lo anterior, será necesario que el Estado dicte medidas para dar efecto a los mencionados derechos, para lo cual deberán considerarse las condiciones propias de cada país.

Con el objeto de ilustrar el sentido que se les ha conferido a ambos derechos, resulta conveniente recurrir a la opinión del Foro Permanente de Asuntos Indígenas del Consejo Económico y Social de las Naciones Unidas ${ }^{61}$, organismo que elaboró una guía que analiza los principios relevantes del Convenio y de la Declaración de las Naciones

60 Tribunal Constitucional, Rol No 309 del 4 de agosto de 2000, considerando 70.

${ }^{61}$ El Foro Permanente en Asuntos Indígenas se encuentra integrado por un panel de 16 expertos en materias indígenas, al cual le corresponde prestar asesoría especializada al Consejo de la ONU, así como formular recomendaciones sobre cuestiones indígenas. 
Unidas sobre Derechos de los Pueblos Indígenas en materias relacionadas con los derechos sobre la tierra y territorios indígenas, y sobre los recursos naturales existentes en ellas ${ }^{62}$.

Esta guía contiene una opinión técnica, elaborada con la asesoría de la OIT, que busca orientar la interpretación de los conceptos jurídicos que el Convenio establece en materia de derechos sobre tierras y territorios.

De acuerdo al Foro Permanente, para reclamar el reconocimiento del derecho de propiedad y de posesión sobre las tierras que tradicionalmente ocupan, se requiere que exista una ocupación tradicional, que debe ser efectiva (real). Lo anterior se sustenta en que el artículo 14 del Convenio utiliza las expresiones "ocupadas por ellos" o "que tradicionalmente ocupan", por lo que se exigiría que la ocupación sea actual o a lo menos reciente. Para el caso que no sea así, el Convenio sólo reconocería un derecho a utilizar dichas tierras o territorios.

En efecto, el artículo $14 \mathrm{~N}^{\circ} 1$ del Convenio se refiere al derecho de propiedad y de posesión que tienen las comunidades respecto de las tierras que "tradicionalmente ocupan", contrastándola con el derecho para que se adopten medidas para salvaguardar su derecho a "utilizar tierras que no estén exclusivamente ocupadas por ellos", pero en las que han tenido un acceso tradicional, según señala el artículo $14 \mathrm{~N}^{\circ} 1$ parte final.

Efectuar esta distinción resulta relevante, por cuanto el derecho a "utilizar" es un derecho de menor jerarquía, que no da derecho a propiedad y se refiere a los casos en que la propiedad pertenece a un tercero, ya sea al Estado o a particulares. Para hacer efectivo este derecho a "utilizar" estos terrenos en que existe propietario legítimo, deberá solicitarse su autorización. Para el caso que se trate de terrenos fiscales que ocupen tradicionalmente los pueblos indígenas, el Estado podría permitir la utilización de dichos terrenos para los fines que se estime, por ejemplo celebrando un convenio de colaboración con las comunidades para permitir el pastoreo, extracción de leña en una reserva nacional $u$ otros en terrenos fiscales.

${ }^{62}$ Economic and Social Council, Permanent Forum on Indigenous Issues, "A Draft Guide on the Relevant Principles Contained in the United Nations Declaration on the Rights of Indigenous Peoples, International Labour Organisation Convention No. 169 and International Labour Organisation Convention No. 107 that Relate to Indigenous Land Tenure and Management Arrangements." (E/c.19/CRP.7.), New York, 2009. http://www.un.org/esa/socdev/unpfii/documents/E_C19_2009_CRP_7.doc. 
En el caso de un terreno privado, dicha utilización podría consentirse mediante una simple autorización (tolerancia) o contrato que permita la utilización de los pueblos indígenas de un terreno privado que es ocupado tradicionalmente para sus actividades. Sin embargo, tal como se ha señalado, en ambos casos dicha utilización no podría dar a lugar a un derecho a reclamar el dominio y posesión.

Lo novedoso del Convenio es que reconoce un derecho a "utilizar" terrenos ajenos, por lo que el Estado de Chile deberá adoptar las medidas legislativas o administrativas para permitir el efectivo ejercicio de ese derecho, lo que no podría afectar derechos adquiridos. En cuanto al derecho de reivindicación, el Convenio impone sobre los gobiernos en el artículo $14 \mathrm{~N}^{\circ} 2$ el deber de tomar medidas necesarias para determinar las tierras que los pueblos "ocupan tradicionalmente" para garantizar su protección. Esta tarea ha sido emprendida por el Estado a través del Fondo de Tierras y Aguas de la Conadi, por lo que ése es el instrumento adecuado para su implementación.

Una segunda precisión de relevancia dice relación con la necesidad de acreditar que las tierras tradicionalmente ocupadas lo son de manera actual o al menos reciente. En efecto, se señala por parte del Panel de Expertos que se requiere que dicha ocupación tradicional sea actual en orden a hacer aplicable esta disposición. Se indica que la inclusión en el artículo 14 (1) de la palabra "exclusivamente" entre las palabras "no estén" y "ocupadas" (en vez de "meramente" no estén ocupadas) significaría que aquellas comunidades que han sido despojadas de sus tierras no gozan del beneficio de esta disposición.

Es así como el documento elaborado por el Panel de Expertos señala: "Esta disposición sugiere que los pueblos indígenas necesitan estar actualmente en posesión de tierras tradicionales, sea como poseedores exclusivos o no, para poder calificar dentro de esta sección [...] La inclusión de la palabra "exclusivos" [...] podría sugerir que los pueblos indígenas que han sido despojados de sus tierras no podrán beneficiarse de esta disposición" $" 63$.

Esta posición también es compartida por la doctrina internacional, que señala que tratándose de derechos de propiedad reclamados por

${ }^{63}$ Traducción nuestra. El texto original señala: "This provision suggests that Indigenous people need to be currently in possession of traditional lands, whether as exclusive possessor or not, in order to qualify under this section [...] The inclusion of the word "exclusively [...] might suggest that indigenous peoples who have been dispossessed of their lands will not have the benefit of this provision". 
indígenas, "estos deben ser capaces de ejercitar algún tipo de control o derecho a disponer, y no una mera práctica tradicional o uso que cambie con la evolución cultural" ${ }^{\prime 4}$.

Cabe señalar que la Corte Suprema, en el caso de la regularización de aguas por parte de la Comunidad de Chusmiza-Usmagama, consideró como elemento clave para acoger la solicitud de regularización, la circunstancia, que constituía un hecho no controvertido, de que el uso de las aguas se habría hecho de manera "ininterrumpida" desde períodos precolombinos hasta nuestros días, lo que se manifiesta por la existencia de socavones, estanques de acumulación, terrazas de cultivos, canales y el mismo asentamiento humano ${ }^{65}$.

De acuerdo con este criterio, no bastaría con señalar que existiría una utilización histórica de aquellos territorios para los efectos de sustentar reclamaciones de propiedad o posesión sobre las tierras, sino que se requiere acreditar la existencia de una conexión entre ese uso tradicional y ancestral con la actualidad al menos reciente.

En cambio el derecho a "utilizar" tierras que no estén exclusivamente ocupadas por ellos significaría un derecho de menor entidad, toda vez que se está reconociendo dominio ajeno, caso en el cual el Convenio sólo reconocería un derecho a utilizar terrenos que pertenecen a terceros. Sin embargo, debido al carácter programático de esta disposición, para hacer efectivo este derecho se requerirá de las adecuaciones legislativas necesarias para permitir dicha utilización respecto de terrenos ajenos, sin perjuicio de las autorizaciones o permisos que sus propietarios puedan otorgar.

En tal sentido, este derecho podría ser reconducido a algunas de las instituciones que el Derecho Civil contempla a propósito de la

${ }^{64}$ Geir Ulfstein, "Indigenous People's Rights to Land", 2004, p. 22. El autor expresa "while the second sentence gives a right of use, the first sentence gives a right to something more than use, namely the rights of ownership and possession. This also implies that within lands coming under first sentence indigenous people shall be able to exercise a form of control or right of disposal, and not just to practise traditional use or use which changes in step with the evolution of their culture" ("mientras la segunda frase da un derecho de uso, la primera da derecho a algo más que el uso, a saber, a derechos de propiedad y posesión. También implica que en los territorios considerados en la primera frase, los indígenas podrán ejercer una forma de control o derecho a disponer, y no sólo ejercer un uso tradicional o un uso que cambie de acuerdo con la evolución de su cultura").

${ }^{65}$ Sentencia de la Exma. Corte Suprema de fecha 25 de noviembre de 2009, Rol $\mathrm{N}^{\circ} 2840 / 2008$. 
utilización o detentación de terrenos ajenos, como ocurre a propósito de las reglas del precario que regula la tenencia de una cosa ajena, sin previo contrato y por ignorancia o mera tolerancia del dueño (artículo 2195 Código Civil), o de los actos de mera tolerancia a propósito de las servidumbres, como es el caso del dueño que tolera que el ganado de su vecino transite por sus tierras o paste en ellas, sin que eso implique imponer la servidumbre de tránsito o pasto en su terreno (artículo 2499 inciso tercero Código Civil).

El reconocimiento a un derecho a utilizar terrenos ajenos a que hace referencia el Convenio debe aplicarse considerando el respeto del ordenamiento jurídico vigente, para lo cual podría recurrirse a mecanismos legales que permitirían garantizarlo, tales como contratos de arrendamiento y constitución de servidumbres voluntarias, en los cuales se garantiza el derecho a utilizar las tierras por parte de las comunidades, pero asegurando al mismo tiempo el derecho de dominio por parte de quien tiene un título justo, esto es, un acto o contrato. De lo contrario, el derecho establecido en el Convenio estaría en contradicción al régimen general de adquisición de la propiedad establecido en Chile.

Sin perjuicio de los mecanismos que deberán desarrollarse para asegurar tanto el respeto del derecho de los indígenas establecido en el Convenio y el respeto de los derechos que reconoce la legislación nacional a los legítimos propietarios de las tierras, deberá considerarse que cualquier mecanismo que pretenda implementarse no podrá alterar los actos o contratos ya celebrados. Esto quiere decir que el derecho reconocido en el Convenio no podrá aplicarse a los contratos (compraventas, concesiones, arrendamientos) que se hubieren válidamente celebrado con anterioridad a la aprobación del Convenio, ya que de lo contrario se estarían afectando derechos adquiridos, cuestión que se encuentra prohibida por la Constitución Política de la República.

\section{X.2. Derecho en relación con la participación y consulta sobre recursos naturales existentes en sus tierras (territorios)}

En cuanto al derecho a obtener por parte del Estado una protección especial de los recursos naturales que se encuentren en sus tierras, a que hace referencia el artículo 15 parte primera del Convenio, éste es un tema que puede acarrear exigencias para el Estado en relación con una obligación de catastrar y proteger esos recursos naturales, lo que 
desde un punto de vista de su aplicación tiene implicancias para la evaluación ambiental de proyectos.

En efecto, el Convenio reconoce que los recursos naturales existentes en tierras indígenas, y por extensión de los existentes en territorios indígenas de acuerdo al artículo 13 (2) del Convenio, merecen un grado de protección especial (artículo 15 parte primera). Esta circunstancia podría hacer exigible al Estado la obligación de efectuar una declaración oficial de dichos recursos como protegidos, por ejemplo mediante una resolución o decreto, procediéndose a identificar o catastrar aquellos recursos, lo que podría tener consecuencias en relación con la exigencia de un Estudio de Impacto Ambiental, por aplicación del artículo 9 letra (b) del Reglamento del SEIA.

De acuerdo a lo expuesto, el titular del proyecto deberá presentar un EIA, cuando éste se localice próximo a recursos protegidos susceptibles de ser afectados, para lo cual se debe considerar la magnitud o duración de la intervención o emplazamiento en o alrededor de áreas donde existan recursos protegidos en forma oficial, según estipula el artículo 9 (b) del Reglamento del SEIA.

Esta exigencia de protección ha sido parcialmente efectuada por el Estado al delimitar los acuíferos que alimentan vegas y bofedales de la I y II Región. En efecto, el año 1992, los artículos 58 y 63 del Código de Aguas fueron modificados ${ }^{66}$ en el sentido de prohibir la exploración y explotación de aguas subterráneas en los acuíferos alimentadores de las vegas y bofedales de la I y II Región. La modificación tuvo como fundamento el hecho de que los acuíferos referidos son el sustento de las actividades agroganaderas y de sobrevivencia de las comunidades andinas, estableciéndose una medida de protección de estos ecosistemas únicos y del manejo y uso ancestral que las comunidades habían hecho de ellos.

Así se agregó un inciso final al artículo 58 del Código de Aguas, en virtud del cual no se permite efectuar exploraciones en terrenos públicos o privados de zonas que alimenten áreas de vegas y de los llamados bofedales en las regiones de Tarapacá y de Antofagasta, sino con autorización fundada de la DGA, la que previamente deberá identificar y delimitar dichas zonas.

En relación con la explotación de las aguas, el artículo 63 del Código de Aguas, que trata las zonas de prohibición para nuevas explota-

${ }^{66}$ Ley N ${ }^{o} 19.145$, publicada en el Diario Oficial el 25 de junio de 1992. 
ciones $^{67}$, declaró como tales las zonas que corresponden a acuíferos que alimenten vegas y los llamados bofedales de las regiones de Tarapacá y de Antofagasta, obligando a la DGA a identificar y delimitar previamente dichas zonas.

En virtud de las modificaciones descritas, a partir del año 1993 la DGA llevó a cabo, en convenio con la Universidad de Chile, Facultad de Ciencias Sociales, un estudio denominado "Identificación y ubicación de áreas de vegas y bofedales de las Regiones I y II", cuyo objetivo principal fue identificar, ubicar geográficamente y caracterizar las vegas y bofedales de dichas regiones.

De acuerdo a los resultados de ese estudio, en 1996 se dictó la Resolución DGA N ${ }^{\circ} 909$ que delimitó dichos acuíferos. Originalmente, en la II Región se protegieron 167 humedales con una superficie asociada de $2.798 \mathrm{~km}^{2}$, equivalentes al $2,22 \%$ de la superficie total de la región. En el año 2003 mediante la Resolución DGA No 529 se modificó la delimitación de estos acuíferos para la II Región, quedando protegidos 228 humedales y una superficie de $5.149 \mathrm{~km}^{2}$ equivalentes al 4,07\% de la superficie total regional ${ }^{68}$. En 2006 fue nuevamente modificada la identificación y delimitación de los acuíferos que alimentan vegas y bofedales en la Región de Antofagasta, mediante la Resolución DGA N ${ }^{\circ} 87^{69}$.

Todo lo anterior puede enmarcarse dentro de esta obligación de proteger especialmente los recursos naturales que se encuentren en las tierras o territorios indígenas, que el Estado ha asumido y que podría comprender una obligación adicional de identificar y otorgar protección oficial a diversos recursos naturales o culturales que pueden ser considerados de valor para las comunidades, tales como menokos, sitios ceremoniales religiosos para el desarrollo de actividades tradicionales, árboles sagrados, cerros, cementerios, etc.

En cuanto al derecho a participar y a ser consultado con relación a los recursos naturales que se encuentren en sus tierras, este tema puede tener amplias repercusiones. Si bien el TC estimó que era una disposición programática y que se enmarcaba en el derecho general

${ }^{67}$ De acuerdo con el artículo 63 del Código de Aguas, la declaración de una zona de prohibición dará origen a una comunidad de aguas formada por todos los usuarios de aguas subterráneas comprendidos en ella.

$68 \mathrm{http}: / /$ www.dga.cl/index.php?option=content\&task=view\&id=168\&Itemi $\mathrm{d}=325$.

${ }^{69}$ Publicado en el Diario Oficial el 1 de junio de 2006. 
de participación que establece el artículo $1^{\circ}$ de la Constitución Política, creemos que este derecho de participación y consulta puede tener mayores consecuencias que las advertidas por el TC.

Con relación a la participación, el Convenio viene a fortalecer el derecho de participación indígena consagrado en la Ley 19.253 en los artículos 34 al 37. Debe considerarse que el Convenio reconoce específicamente el derecho a participar en la conservación de los recursos naturales, por lo que se está explícitamente reconociendo la existencia de un interés legítimo por parte de los pueblos indígenas y tribales para instar por la protección de estos recursos. En este sentido, el Convenio viene a clarificar que constituye una "cuestión indígena", aquellos referidos a la conservación de los recursos naturales existentes en sus tierras y territorios.

Este reconocimiento a participar en temas de conservación de los recursos naturales ha sido fortalecido con las recientes modificaciones incorporadas a la Ley $N^{\circ} 19.300$ por la Ley $N^{\circ} 20.417$ que crea la Nueva Institucionalidad Ambiental ${ }^{70}$.

De acuerdo a estas modificaciones, es posible que proyectos tramitados como Declaraciones de Impacto Ambiental (DIA) contemplen participación ciudadana en los casos en que se produzcan cargas ambientales, esto es, externalidades negativas para las localidades próximas (art. 30 bis Ley $\mathrm{N}^{\circ}$ 19.300). Esta situación permitiría incorporar la consulta indígena incluso respecto de proyectos que no alteran los sistemas de vida o costumbres de las comunidades, o no den lugar a relocalización, sino que generan impactos menores o indirectos (cargas ambientales). Sin embargo, en estos casos la consulta dependerá de que la soliciten dos organizaciones ciudadanas con personalidad jurídica o diez personas naturales directamente afectadas ${ }^{71}$.

Con las modificaciones incorporadas por la Ley $\mathrm{N}^{\circ} 20.417$, las comunidades indígenas también se han visto fortalecidas en sus dere-

${ }^{70}$ Ley $\mathrm{N}^{\circ} 20.417$ que crea el Ministerio del Medio Ambiente, el Servicio de Evaluación Ambiental y la Superintendencia del Medio Ambiente, publicada en el Diario Oficial el 26 de enero de 2010 ..

${ }^{71}$ Artículo 30 quinquies de la Ley $\mathrm{N}^{\circ}$ 19.300. Actualmente por Instructivo de la Dirección Ejecutiva de Conama (hoy Servicio de Evaluación Ambiental) № 100745 de 12 de marzo de 2010 que Modifica Anexo Asociado a las Instrucciones acerca de la Aplicación de las Modificaciones Introducidas por la Ley № 20.417 a la Ley № 19.300, se estableció que la participación ciudadana en las DIA se encontraba pendiente en su vigencia a la espera de la dictación del respectivo reglamento. 
chos de seguimiento de los proyectos sometidos al SEIA. En efecto, el nuevo artículo 25 quinquies incorporados a la Ley $\mathrm{N}^{\circ} 19.300$ establece que los que se consideren "directamente afectados" podrán solicitar la revisión de la RCA, para el caso en que las variables evaluadas y contempladas en el plan de seguimiento, sobre las cuales fueron establecidas las condiciones o medidas, hayan cambiado sustantivamente con relación a lo proyectado o no se hayan verificado, con el objeto de adoptar las medidas necesarias para corregir dichas situaciones.

Esta hipótesis permitiría a las comunidades aledañas que sufran afectación en sus derechos solicitar la adecuación del proyecto, de manera que se adopten las medidas necesarias para corregir los impactos no previstos.

Además de las instancias citadas, una vez que entre en funcionamiento la Superintendencia del Medio Ambiente ${ }^{72}$, las comunidades contarán con la posibilidad de que dicho organismo fiscalice a los proyectos o actividades que generen efectos no previstos en la evaluación ambiental.

De acuerdo al artículo $3^{\circ}$ letra (h) de la ley que crea la Superintendencia del Medio Ambiente, dicha repartición tendrá la facultad de suspender transitoriamente las autorizaciones de funcionamiento contenidas en las Resoluciones de Calificación Ambiental o adoptar otras medidas urgentes y transitorias, para el resguardo del medio ambiente, cuando la ejecución u operación de los proyectos o actividades genere efectos no previstos en la evaluación y como consecuencia de ello se pueda generar un daño inminente y grave para el medio ambiente. Esta medida también puede adoptarse en caso de incumplimiento grave de las condiciones impuestas en la RCA, que pudiera generar un daño grave e inminente para el medio ambiente, según dispone el artículo 3 letra $(\mathrm{g})$.

En otras palabras, para el caso que se detecte la generación de impactos no previstos o exista un riesgo de generarse un daño grave al medio ambiente de las comunidades indígenas, éstas se encontrarán facultadas para denunciar esta situación ante la Superintendencia, la cual de manera transitoria podrá suspender la RCA y adoptar las medidas urgentes y transitorias que se estimen pertinentes (artículo 32 de la Ley 19.880).

${ }^{72}$ La Superintendencia de Medio Ambiente entrará en vigencia cuando comiencen a regir los tribunales ambientales. 
Lo anterior permitiría sostener que de acuerdo al actual ordenamiento jurídico, las comunidades indígenas tienen resguardado su derecho a participar en la conservación de los recursos naturales que se encuentren en sus tierras y territorios.

Sin perjuicio de lo señalado, cabe indicar que durante la discusión parlamentaria de la aprobación del Convenio, la opinión manifestada por el Ejecutivo se inclinó a formalizar la consulta a través de la creación de un nuevo permiso. Así en el informe de la Comisión de Relaciones Exteriores dirigida a la Cámara de Diputados, el entonces ministro (s) José Miguel Insulza anunció que "se harán las adecuaciones legales internas para establecer el permiso del indígena o de una autoridad, con lo que se conciliará el Convenio con el derecho de la Constitución Política"73.

De esta forma, es eventualmente factible que la consulta indígena concluya en la creación de un permiso especial en los casos que se contemple la utilización de recursos naturales que se encuentren en sus tierras o territorios.

\section{X.3. Derecho a participar de los beneficios y a ser indemnizados}

Con relación al derecho a participar de los beneficios que reporten tales actividades, creemos que la actual legislación ya establece los mecanismos adecuados para garantizar su reconocimiento, por lo menos desde un punto de vista de los beneficios ambientales.

En efecto, la legislación ambiental ha instaurado el mecanismo del Estudio de Impacto Ambiental con el objetivo preciso de establecer medidas o acciones para "impedir o minimizar sus efectos significativos adversos", que el proyecto o actividad presente o genere, según define el artículo 2 letra (i) de la Ley 19.300.

Para estos efectos, la legislación ambiental reconoce la necesidad de evaluar los impactos ambientales adversos y compensar dichos impactos mediante un efecto positivo alternativo, estableciendo las medidas de compensación correspondientes, según establece expresamente el artículo 60 del Reglamento del SEIA. En este escenario, el derecho a participar de los beneficios que reporten tales actividades debe entenderse resguardado por lo menos desde el punto de vista ambiental.

${ }^{73}$ Congreso Nacional, Cámara de Diputados, Comisión de Relaciones Exteriores, Asuntos Interparlamentarios e Integración Latinoamericana, Informe $\mathrm{N}^{\mathrm{o}}$ 223-10. 
En cuanto al derecho a participar de los beneficios de orden económico o monetario que el proyecto genere como consecuencia de la explotación de los recursos naturales que se encuentren en las tierras indígenas o territorios, corresponderá al Estado a través de su política de gasto social entregar los recursos a las comunidades indígenas, ya sea a través de subsidios directos o programas sociales y productivos diseñados directamente en beneficio de dichas comunidades.

Desde un punto de vista de efectividad, eficiencia y conveniencia social de establecer un modelo de participación económica en base a las negociaciones o acuerdos que alcancen las partes, cabe señalar que la experiencia ha demostrado la inconveniencia de tal solución. En efecto, la existencia de pagos directos a las comunidades podría generar situaciones de corrupción y tráfico de influencias. Por otro lado, el pago de dineros a las comunidades ha sido utilizado como herramienta de extorsión para condicionar la aprobación o rechazo de un proyecto, lo que ha derivado en fragmentación social de las propias comunidades, generándose una división entre quienes aceptan la compensación y quienes no.

En definitiva, la fórmula de traspaso de dineros directos desde las empresas hacia las comunidades mediante procesos de negociación o acuerdos tiene el riesgo de generar corrupción, ineficiencia en el uso de los recursos aportados, caudillismo y fragmentación social. Lo anterior es sin perjuicio de lo que las empresas decidan hacer en forma voluntaria en el contexto de la Responsabilidad Social de la Empresa (RSE).

Con relación al derecho a ser indemnizado de cualquier daño que puedan sufrir como consecuencia de esas actividades, también creemos que este derecho ya se encuentra resguardado en el derecho común que reconoce como principio general que todo aquel que sufre un daño debe ser resarcido por los perjuicios causados.

Con todo, resulta conveniente clarificar la expresión utilizada por el Convenio, esto es, que resulta indemnizable "cualquier daño", por cuanto conforme al sistema general de responsabilidad establecido en Chile se requiere probar la culpabilidad o negligencia de quien causa el daño o perjuicio. En este sentido, la expresión cualquier daño debe entenderse que será procedente en la medida que medie una responsabilidad subjetiva, ya que el principio la responsabilidad objetiva en Chile no tiene cabida por regla general.

En cuanto al tipo de daños, deberá distinguirse si existen derechos de propiedad sobre los recursos naturales afectados, ya que sólo 
en ese caso podrá demandarse una indemnización de perjuicios por los daños ocasionados en el patrimonio de las comunidades.

Distinta es la situación en que las comunidades demanden una acción meramente reparatoria del daño ambiental producido. En este caso, el Convenio, al contemplar un derecho para instar por la protección de los recursos naturales que se encuentren en sus tierras, está reconociendo un interés legítimo para demandar aunque no tengan la calidad de propietarios de dichos recursos, toda vez que el Convenio no se restringe a los recursos naturales que pertenezcan a la comunidad, sino que comprende también a aquellos que se encuentren en sus tierras.

\section{COMENTARIOS FINALES}

El reconocimiento de derechos especiales a los pueblos indígenas supone el respeto de la dignidad de los mismos, como su plena capacidad para decidir y controlar su destino a través de sus propias instituciones y determinar el control de sus propios asuntos. Sin embargo, estos derechos y ventajas no suponen el reconocimiento a la "autodeterminación", en el sentido que se les haya conferido poderes públicos o soberanos, sino que tales derechos deben ser ejercicios en forma igualitaria con los demás grupos que forman parte de la sociedad.

Como consecuencia de lo anterior, los derechos especiales reconocidos a los pueblos indígenas deben ser ejercidos en el contexto de la institucionalidad legal establecida en el ordenamiento jurídico vigente. Este contexto conlleva a que las altas expectativas de las comunidades surgidas como consecuencia de la vigencia del Convenio poco a poco se hayan ido adecuando a la realidad normativa e institucional vigente.

Lo anterior ha quedado demostrado tempranamente desde el dictamen del Tribunal Constitucional hasta los diversos fallos emitidos por la Corte Suprema que han reconducido el derecho de consulta indígena al estatus de participación aplicable a todos los chilenos, sin distinción de origen étnico.

La decisión de implementar procedimientos o instancias especiales de consulta, como la existencia de un permiso indígena, supondrá la existencia de una voluntad política y social de avanzar en la incorporación de nuevos mecanismos de participación o el perfeccionamiento de los existentes. 


\section{REFERENCIAS}

\section{Documentos y textos legales:}

BIT (Bureau International du Travail), ILO (International Labour Office), Oficio ACD 5-169 de 6 de febrero de 2008.

Comisionado Presidencial para Asuntos Indígenas. "Código de Conducta Responsable para Inversiones en Tierras y Áreas de Desarrollo Indígena.” Documento de Discusión. Ministerio de Planificación (abril de 2009).

Conadi. "Implementación del Convenio N ${ }^{\circ} 169$ de la OIT". Segunda Parte. Documento sin fecha.

Conama. Instructivo Dirección Ejecutiva de CONAMA N ${ }^{\circ} 100745$ de 12 de marzo de 2010. Modifica Anexo Asociado a las Instrucciones acerca de la Aplicación de las Modificaciones Introducidas por la Ley $N^{\circ} 20.417$ a la Ley $N^{\circ} 19.300$.

Congreso Nacional, Cámara de Diputados, Comisión de Relaciones Exteriores, Asuntos Interparlamentarios e Integración Latinoamericana. Informe $\mathrm{N}^{\circ}$ 223-10.

Congreso Nacional, Senado. Sesión de discusión de la Ley Indígena $\mathrm{N}^{\circ} 10$, legislatura del 13 de julio de 1993.

Contraloría General de la República. Dictamen No 13.432 de fecha 27 de marzo de 2008. - Dictamen No 70292 de fecha 17 de diciembre de 2009.

Corte de Apelaciones de Concepción. Sentencia de 1 de diciembre de 2010. Recurso de Protección Rol N ${ }^{\circ}$ 401/2010 caratulado Meza Moncada y otros contra COREMA Región del Bío Bío.

Corte de Apelaciones de Puerto Montt. Sentencia de 27 de julio de 2010. Recurso de Protección Rol No 36/2010 caratulado Comunidad Mapuche Huilliche Pepiukelen de Pargua en contra de la Empresa Pesquera Los Fiordos Ltda.

Corte de Apelaciones de Temuco. Sentencia de 27 de septiembre de 2010. Recurso de protección Rol N 1155-2010 caratulado Comunidad Indígena Mapuche Hueche Huenulaf contra el Ministerio de Obras Públicas.

Corte Suprema. Sentencia de fecha 25 de noviembre de 2009. Recurso de Protección Rol $\mathrm{N}^{\circ}$ 2840/2008 caratulado Alejandro Papic Domínguez con comunidad Indígena Aimara Chusmiza y Usmagama.

Sentencia de fecha 30 de noviembre de 2009. Recurso de Protección Rol No 7287/2009 caratulado Francisca Linconao Huircapán con Sociedad Palermo Limitada.

- Sentencia de fecha 17 de mayo de 2010. Recurso de Protección Rol N¹525/2010 caratulado Puelman Ñanco, Mariano y otro contra Comisión Regional del Medio Ambiente de la Araucanía.

- Sentencia de fecha 14 de octubre de 2010. Recurso de Protección Rol $\mathrm{N}^{\circ}$ 4078/2010 caratulado Nahuelpán Guilitraro, representante Comunidad Indígena Villa Nahuel y otros contra Comisión Regional del Medio Ambiente Región de Los Ríos.

DIA (Declaración de Impacto Ambiental). BHP Chile Inc.: Programas de Exploración Turi.

DIA (Declaración de Impacto Ambiental). Ingeniería Seawind Sudamérica Ltda.: Proyecto Eólico Quillagua de 100 MW .

DIA (Declaración de Impacto Ambiental). Minera Santa Rosa SCM: Prospección Minera Lobo Marte Etapa II. 
DIA (Declaración de Impacto Ambiental). Ministerio de Obras Públicas: Ampliación y Mejoramiento Aeropuerto El Loa Calama - II Región de Antofagasta.

DIA (Declaración de Impacto Ambiental). Municipalidad de Lanco: Estación de Transferencia de Residuos Sólidos Lanco-Panguipulli.

DS $N^{\circ}$ 07/2008 de 1 de febrero de 2008 de Mideplan que designa Comisionado Presidencial para Asuntos Indígenas a don Rodrigo Egaña Baraona. Diario Oficial, 25 de abril de 2008.

DS $\mathrm{N}^{\circ} 70 / 2008$ de 9 de mayo de 2008 de Mideplan que crea el Consejo Ministerial para Asuntos Indígenas. Diario Oficial, 24 de junio de 2008.

DS $N^{\circ} 97 / 2009$ de 26 de agosto de 2009 de Minsegpres que designa Ministro Coordinador en Materias Indígenas al Ministro Secretario General de la Presidencia José Antonio Viera-Gallo. Diario Oficial, 26 de septiembre de 2009

DS N ${ }^{\circ} 124 / 2009$ de 04 de septiembre de 2009 de Mideplan que Reglamenta el Artículo 34 de la Ley № 19.253 a Fin de Regular la Consulta y la Participación de los Pueblos Indígenas. Diario Oficial, 25 de septiembre de 2009.

Economic and Social Council, Permanent Forum on Indigenous Issues. "A Draft Guide on the Relevant Principles Contained in the United Nations Declaration on the Rights of Indigenous Peoples, International Labour Organisation Convention No. 169 and International Labour Organisation Convention No. 107 that Relate to Indigenous Land Tenure and Management Arrangements". New York, 2009.

EIA (Evaluación de Impacto Ambiental). Sociedad Chilena del Litio: Modificaciones y Mejoramiento del Sistema de Pozas de Evaporación Solar en el Salar de Atacama.

Gobierno de Chile. Memoria acerca de las medidas adoptadas para dar efectividad a las disposiciones del Convenio. Período del 15 de septiembre de 2009 al 15 de septiembre de 2010. 1 de septiembre de 2010.

Ley Indígena $N^{\circ} 19.253$ que Establece Normas sobre Protección, Fomento y Desarrollo de los Indígenas, y Crea la Corporación Nacional de Desarrollo Indígena. Diario Oficial, 5 de octubre de 1993.

Ley $N^{\circ} 20.417$ que crea el Ministerio del Medio Ambiente, el Servicio de Evaluación Ambiental y la Superintendencia del Medio Ambiente. Diario Oficial, 26 de enero de 2010.

ONU. Declaración sobre Derechos de los Pueblos Indígenas. Asamblea General. Sesión 61 del 13 de septiembre de 2007.

Presidencia de la República. Instructivo Presidencial № 005 de 25 de junio de 2008. Instructivo Presidencial que Implementa Iniciativas de Re-Conocer Pacto Social por la Multiculturalidad.

Tribunal Constitucional. Sentencias Rol No 309 del 4 de agosto de 2000 y Rol No 1050/2008 de 3 de abril de 2008 .

\section{Libros y artículos en libros o en publicaciones periódicas}

Anaya, James. "Los Derechos de los Pueblos Indígenas". En Felipe Gómez Isa (director) y José Manuel Pureza, La Protección Internacional de los Derechos Humanos en los Albores del Siglo XXI. Bilbao: Centro de Estudos Sociais, Universidad de Deusto, 2004. 
Furze, Brian. "Institution Building and Community Consultation". En B. Furze et al., Culture, Conservation, and Biodiversity: The Social Dimension of Linking Local Level Development and Conservation through Protected Areas. New York: John Wiley Editores, 1996.

Khor, Martin. Intellectual Property, Biodiversity and Sustainable Development, Resolving the Difficult Issues. New York: Zed Books, 2002.

Montt Oyarzún, Santiago y Manuel Matta Aylwin. "Una Visión Panorámica al Convenio OIT 169 y su Implementación en Chile”. Estudios Públicos 121 (verano 2011).

OIT. Consejo de Administración. Convenio N 169 Sobre Pueblos Indígenas y Tribales en Países Independientes. Ginebra, 7 junio de 1989.

Convenio $N^{o} 169$ sobre Pueblos Indígenas y Tribales: Un Manual. Proyecto para Promover la Politica de la OIT sobre Pueblos Indígenas y Tribales. Ginebra: OIT, 2003.

- Departamento de Normas Internacionales del Trabajo. Una Guía sobre el Convenio $N^{\circ}$ 169. Ginebra: OIT, 2009.

Rodríguez-Piñero Luis. "Cuando Proceda: Vigilancia y Aplicación de los Derechos de los Pueblos Indígenas según la Declaración”. En Claire Chambers y Rodolfo Stavenhagen (editores), El Desafio de la Declaración: Historia y Futuro de la Declaración de la ONU sobre Pueblos Indígenas. Publicaciones IWGIA 2010.

Ulfstein, Geir. "Indigenous People's Rights to Land". Max Planck Yearbook of United Nations $\mathrm{N}^{\circ} 8$ (2004).

World Bank Group, International Finance Corporation. "ILO Convention 169 and the Private Sector. Questions and Answers for IFC Clients". Marzo de 2007.

Yáñez, Nancy y Raúl Molina . La Gran Minería y los Derechos Indígenas en el Norte de Chile. Santiago: LOM Ediciones, 2008. 